\title{
Intestinal Microbiota: A Novel Target to Improve Anti-Tumor Treatment?
}

\author{
Romain Villéger $1, *,+\left(\mathbb{C}\right.$, Amélie Lopès $1,2,+\left(\mathbb{0}\right.$, Guillaume Carrier $1,3 \oplus$, Julie Veziant ${ }^{1,4,5}$, \\ Elisabeth Billard ${ }^{1}\left({ }^{\infty}\right.$, Nicolas Barnich ${ }^{1}{ }^{\circledR}$, Johan Gagnière ${ }^{1,4,5}$, Emilie Vazeille ${ }^{1,5,6}$ and \\ Mathilde Bonnet ${ }^{1}$ (1) \\ 1 Microbes, Intestin, Inflammation et Susceptibilité de l'Hôte (M2iSH) UMR 1071 Inserm/Université Clermont \\ Auvergne, USC-INRA 2018, CRNH Auvergne, F-63000 Clermont-Ferrand, France; \\ amelie.lopes0703@gmail.com (A.L.); guillaume.carrier@icm.unicancer.fr (G.C.); \\ jveziant@chu-clermontferrand.fr (J.V.); elisabeth.billard@uca.fr (E.B.); nicolas.barnich@uca.fr (N.B.); \\ jgagniere@chu-clermontferrand.fr (J.G.); Emilie.VAZEILLE@uca.fr (E.V.); mathilde.bonnet@uca.fr (M.B.) \\ 2 Biologics Research, Sanofi R\&D, 94400 Vitry-Sur-Seine, France \\ 3 Surgical Oncology Department, Institut du Cancer de Montpellier (ICM), Univ Montpellier, \\ 34298 Montpellier, France \\ 4 Service de Chirurgie Digestive, CHU Clermont-Ferrand, Inserm, Université Clermont Auvergne, \\ 63003 Clermont-Ferrand, France \\ $53 i H P, C H U$ Clermont-Ferrand, Inserm, Université Clermont Auvergne, 63003 Clermont-Ferrand, France \\ 6 Service d'Hépato-gastro-entérologie, CHU Clermont-Ferrand, Inserm, Université Clermont Auvergne, \\ 63003 Clermont-Ferrand, France \\ * Correspondence: romain.villeger@uca.fr \\ + These authors contributed equally to this work.
}

Received: 30 August 2019; Accepted: 13 September 2019; Published: 17 September 2019

check for updates

\begin{abstract}
Recently, preclinical and clinical studies targeting several types of cancer strongly supported the key role of the gut microbiota in the modulation of host response to anti-tumoral therapies such as chemotherapy, immunotherapy, radiotherapy and even surgery. Intestinal microbiome has been shown to participate in the resistance to a wide range of anticancer treatments by direct interaction with the treatment or by indirectly stimulating host response through immunomodulation. Interestingly, these effects were described on colorectal cancer but also in other types of malignancies. In addition to their role in therapy efficacy, gut microbiota could also impact side effects induced by anticancer treatments. In the first part of this review, we summarized the role of the gut microbiome on the efficacy and side effects of various anticancer treatments and underlying mechanisms. In the second part, we described the new microbiota-targeting strategies, such as probiotics and prebiotics, antibiotics, fecal microbiota transplantation and physical activity, which could be effective adjuvant therapies developed in order to improve anticancer therapeutic efficiency.
\end{abstract}

Keywords: intestinal microbiota; chemotherapy; probiotics; cancer; radiotherapy; anticancer treatment; surgery; microbiome; adjuvant therapies

\section{Introduction}

Cancer is among the leading causes of mortality worldwide. Although the death rate from cancer in the United-States has declined steadily over the past 25 years, the American Cancer Society has estimated a total of 1,762,450 new cancer cases and 606,880 deaths from cancer to occur in the country in 2019. It is estimated that microorganisms could be associated with $15 \%$ to $20 \%$ of cancers [1]. In the recent years, evidence from numerous studies has pointed to the role of commensal microbes as key determinants of health or pathologic conditions, including cancer [2]. The human microbiota is made 
up of trillions of cells, including bacteria, viruses, and fungi. As the largest population of microbes resides in the gut, intestinal microbiota has been widely studied.

The gut microbiome is involved in many areas of human health, from providing nutrients and vitamins, to protecting against pathogens, immune system development and epithelial mucosa homeostasis [3]. Given its central functions, the role of the gut microbiome as a contributor to colorectal carcinogenesis has been well studied [4-6]. However, because of the complex bidirectional relationship between microbiota and host, the pro-carcinogenic mechanisms have only been partially characterized. As summarized by Zitvogel et al. [7], the gut microbiome can contribute to oncogenesis through several mechanisms: a) by a direct oncogenic effect of microorganisms and their products, b) by altering circulating metabolites which, in turn, become pro-carcinogenic, c) by stimulating the synthesis of trophic factors by the host, and finally d) by disrupting host cancer immunosurveillance through the induction of pro-inflammatory and immunosuppressive pathways [7]. In addition to its pro-carcinogenic properties, the intestinal microbiota has been suspected to affect the efficacy of different therapeutic strategies including surgery, chemotherapy, radiotherapy and immunotherapy [8]. Indeed the gut microbiome has been shown to participate in the resistance to a wide range of anticancer treatments [9-11]. Interestingly, these effects have been described on colorectal cancer, but also in other types of malignancies developed at a distance from the gut, such as melanoma, ovarian and lung cancers, pancreatic ductal adenocarcinoma, and sarcoma [9-11].

In the first part of this review, we summarized the impact of the gut microbiome on the efficacy of various anticancer therapies including chemotherapy, immunotherapy, radiotherapy and surgery. In the second part, we described the microbiota-targeting strategies developed in order to improve anticancer-therapeutics efficiency.

\section{Intestinal Microbiota Impacts on Efficacy of Cancer Therapies}

Recent preclinical and few clinical studies focusing on several types of cancer strongly support the key role of the gut bacteria in the modulation of host response to anti-tumor drugs, especially chemotherapy and immunotherapy [12]. Studies have suggested that gut microbes play a significant role in anticancer therapy response by modulating drug efficacy, abolishing the anticancer effect, and mediating toxicity. Although the mechanisms are not well understood, some of them have been described as the "TIMER" framework mechanism for Translocation, Immunomodulation, Metabolism, Enzymatic degradation and Reduced diversity $[12,13]$. In this section, we summarized the role of commensal microbes in modulating cancer therapies efficacy, resistance and toxicity.

\subsection{Chemotherapy}

Gut microbiota seem to be implicated on chemotherapy efficacy through numerous mechanisms, including xenometabolism, immune interactions, and altered community structure [13].

The gut microbiome is able to directly modify or metabolize some xenobiotics such as anticancer drugs. This microbe-mediated xenometabolism could be linked to an increase of the chemotherapeutic component toxicity, leading to a decrease in treatment efficacy [14-17]. The most serious potential case of toxicity associated with death was reported in Japan following 5- fluorouracil (5-FU)sorivudine bi-therapy and involved Bacteroides spp. Indeed Bacteroides species, dominant members of intestinal microbiota, have a high activity of sorivudine conversion to an intermediate (BVU), which inhibits the degradation of 5-FU and results in its accumulation in the blood and then in a higher toxicity (Figure 1) $[15,18]$. Bacteroides species and other $\beta$-glucuronidase-producing bacteria, such as Faecalibacterium prausnitzii and Clostridum spp., have been associated with the accumulation of irinotecan active metabolite (SN-38) in the gut, leading to diarrhea (Figure 1) [14,16]. Germ Free (GF) mice exhibit less gut damage than conventional mice after irinotecan administration, showing the role of the microbiota on these side effects [19]. Moreover, this could be amplified by the impact of chemotherapeutic drugs on gut and oral microbiota composition itself. Studies in mice have shown that 5-FU therapy induced intestinal dysbiosis with an increase of Staphylococcus and Clostridium 
species and a decrease of Enterobacteriaceae, Lactobacillus and Bacteroides [20]. In the same way, severe side effects, such as intestinal mucositis induced by doxorubicin or 5-FU or irinotecan, have been correlated with dysbiosis in the microbiota of the gut and oral cavity [20-22]. In conclusion, following treatment, a decrease in microbiota diversity and richness, as well as dysbiosis, could exacerbate severe side effect in murine models of cancer and in cancer patients [23-28]. This hypothesis has been reinforced by recent studies showing that microbiome modulation through alimentation or probiotic supplementation could reduce the chemotherapy toxicity and subsequent side effects in mice and humans (see below) [17,29-31].

In addition to its role in chemotherapy side effects, gut microbiota also impacts chemotherapy efficacy in pre-clinical models of various subcutaneous solid tumors such as melanoma, lung cancer, colon and sarcoma [10,11,32-34]. Two mechanisms have been identified: remote immune modulations or/and bacterial translocation in lymphoid organs. Among the pioneer studies, lida et al. [10], described the oxaliplatin (OXA) chemoresistance of colon carcinoma and lymphoma in GF or antibiotics-treated mice, in comparison to specific-pathogen-free (SPF) mice. Although the microbial species involved have not been specifically identified, the importance of reactive oxygen species (ROS) producing myeloid anti-tumor cells in the efficacy of OXA has been demonstrated (Figure 1) [10]. Similar results were observed with cyclophosphamide (CTX) treatment, an alkylating agent used for the treatment of lymphomas and solid tumors and known to modulate the immune microenvironment of tumors by reducing regulatory T cells (Tregs) and increasing Th1 and Th17 cells [11,32-34]. The CTX efficacy has been shown to be negatively correlated with dysbiosis induced by antibiotic treatment. The authors highlight the positive key role of both Enterococcus hirae and Barnesiella intestinihominis in the CTX response in non-antibiotic treated mice. E. hirae has been shown to translocate from the gut to lymph nodes and to induce Th1 and pathogenic Th17 responses which were mandatory for the anti-tumor activity of CTX (Figure 1). B. intestinihominis, which is accumulated in the colon, improves systemic amount of Th1 and Tc1, polyfunctional $\mathrm{CD} 8^{+}$cytotoxic T-cells subpopulation, associated with an increase of IFN-y-producing $\gamma \delta$ tumor infiltrating-lymphocytes (TILs) which could also increase the anti-tumor effect of CTX (Figure 1) [11,32,35].

Chemotherapy efficacy can also be directly modulated by intratumoral bacteria through their active metabolic functions (Figure 1) [36-40]. In vitro studies showed a decreased anti-tumoral efficacy of pyrimidine nucleoside analogues in Mycoplasma hyorhinis-infected cell lines. Indeed, these anticancer drugs can be directly degraded in tumor cell by mycoplasma thymidine phosphorylase [36]. The cytostatic activity of the drugs was restored by a specific inhibitor of mycoplasma thymidine phosphorylase (Figure 1) [40]. Moreover, it has been shown that cytidine deaminase-harboring bacteria, such as gammaproteobacteria, are involved in the gemcitabine (GTB) and OXA resistance of mice colorectal tumors [39] (Figure 1). The presence of these bacteria and their role on anti-tumoral GTB activity have also been reported in human pancreatic ductal adenocarcinoma $[37,38]$. Local intratumoral microbiota can also indirectly impact the efficacy of chemotherapy through the modulation of innate immunity. Actually, it has been shown that chemoresistance to 5-FU or OXA was mediated by the activation of autophagy by Fusobacterium nucleatum in colorectal cell lines (HCT116 and HT29), xenograft mice models, and colon cancer (CRC) patients [41]. This activation of autophagy was dependent on the stimulation of the TLR4/MyD88 innate immune pathway. A recent study by Zhang et al. confirmed the association between 5-FU chemoresistance and F. nucleatum colonization (Figure 1) in CRC patients [42]. This work described the involvement of the TLR4/NF- $\mathrm{BB}$ pathway activation which led to the overexpression of BIRC3 (Baculoviral IAP Repeat Containing 3), a member of apoptosis' inhibitor proteins known to be involved in the chemoresistance of several cancers [42,43].

All these data suggest that the gut microbiota appears to be an essential biomarker to consider for improving chemotherapy regimens. Further clinical studies will be performed to evaluate these innovative markers. 

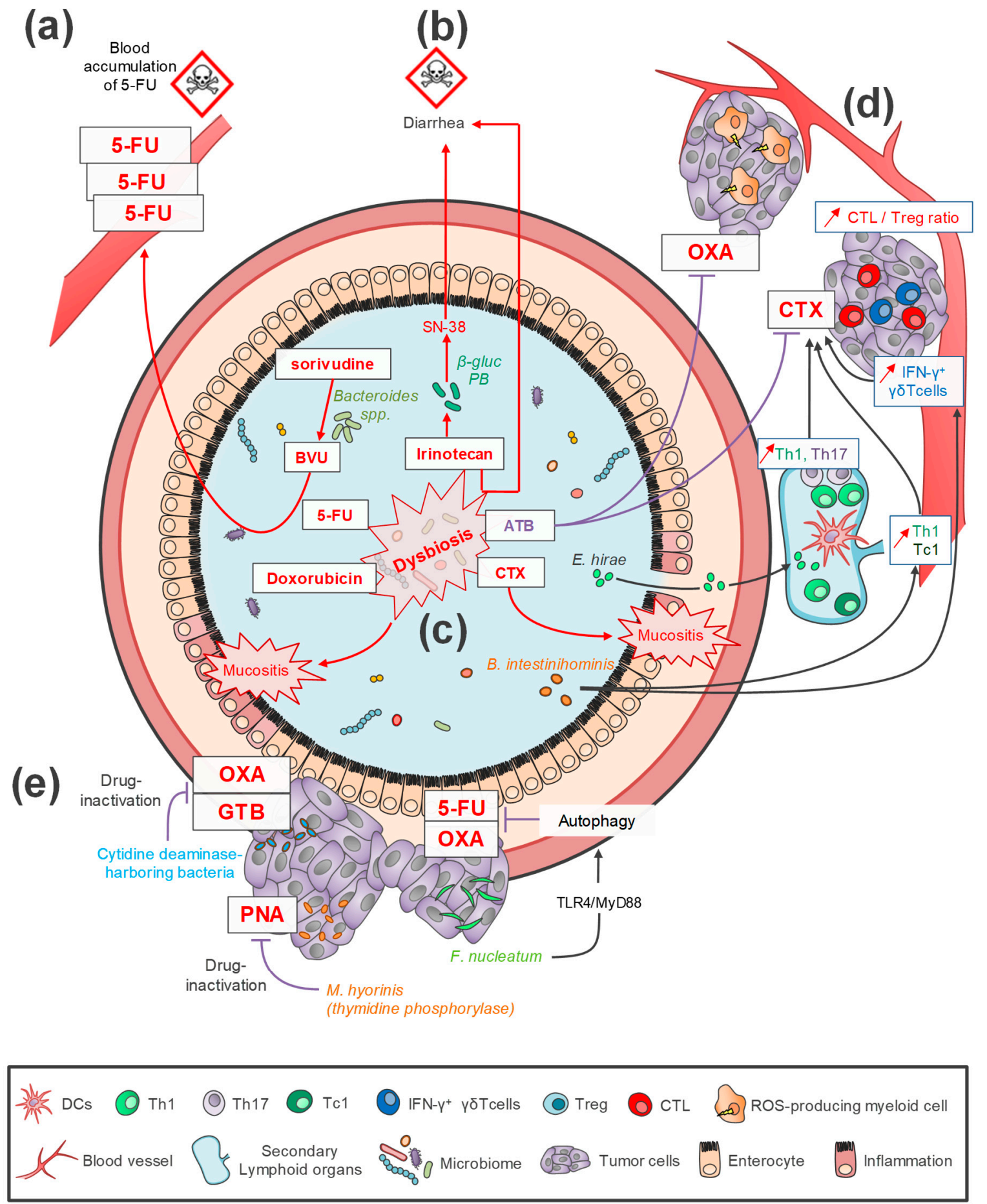

Figure 1. Impacts of intestinal microbiota on chemotherapy toxicity and efficacy. (a,b) Microbe-mediated xenometabolism could be linked to an increase of chemotherapy toxicity. (a) Bacteroides species would convert sorivudine into an intermediate component (BVU), which inhibits the degradation of 5-FU, leading to its toxic accumulation in the blood. (b) The $\beta$-glucuronidase-producing bacteria $(\beta$-gluc- $P B)$ could induce an increase of the irinotecan active metabolite (SN-38) in the gut, which is associated with diarrhea. (c) Chemotherapy treatment could induce dysbiosis (microbial composition alteration), as has been noticed for doxorucibin, 5-FU, cyclophosphamide (CTX), and irinotecan. A dysbiosis could impact chemotherapy efficacy and/or side effects (diarrhea, mucositis, etc.). (d) Gut microbiota could impact chemotherapy efficacy by immune modulations or/and bacterial translocation to lymphoid organs. OXA chemoresistance has been described in antibiotics (ATB)-treated mice and correlated to 
a decrease of ROS-producing myeloid anti-tumor cells. The ATB-induced dysbiosis could also decrease the efficacy of CTX. Contrariwise, Enterococcus hirae, known to translocate from the gut to lymphoid organs following CTX-induced mucositis, could stimulate the anti-tumor activity of CTX by inducing Th1 and pTh17 responses and increasing the intratumoral cytotoxic T-cells (CTL)/ Tregs ratio. Barnesiella intestinihominis could improve systemic amount of Th1 and Tc1 and the intratumoral level of IFN- $\gamma$-producing $\gamma \delta$ TILs (IFN- $\delta^{+} \gamma \delta$ T cells), leading to an increase of CTX efficacy. (e) Intratumoral bacteria could modulate the treatment efficacy. Mycoplasma hyorhinis can directly degrade the pyrimidine nucleoside analogues (PNA) through its thymidine phosphorylase activity. Similarly, gemcitabine (GTB) and OXA inactivation could be due to cytidine deaminase-harboring bacteria. The activation of autophagy via the stimulation of the innate immune pathway TLR4/MyD88 by intratumoral bacterial, such as Fusobacterium nucleatum, could also be involved in the chemoresistance to 5-FU or OXA.

\subsection{Immunotherapy}

The important role of gut microbiota on immunotherapy efficacy was first shown in two studies which highlighted the involvement of the complex crosstalk between bacteria and immune host response in anti-tumor activity [10,44]. The first study by Paulos et al. [44] showed that the efficacy of anti-tumor $\mathrm{CD} 8^{+} \mathrm{T}$ cells adoptive transfer in a melanoma murine model was strongly increased after the total body irradiation of mice through the translocation of gut bacteria into mesenteric lymph nodes. The microbial lipopolysaccharide (LPS) release induced by irradiation activated innate immune response by TLR4 pathway stimulation and then boosted anti-tumor $\mathrm{CD}^{+} \mathrm{T}$ cells, while antibiotic treatment or LPS neutralization (with polymyxin B) were associated with a decrease of anti-tumor response [44]. This effect of gut microbial composition on anti-tumor $\mathrm{T}$ cells adoptive transfer has been recently confirmed in B-cell lymphoma, and in cervix and lung tumor mice models $[33,45]$. The second study, led by Iida et al. [10], described, in MC38 colon carcinoma and B16 melanoma subcutaneous cancer murine models, that antibiotic treatment impaired the efficacy of the anti-IL-10/CpG oligodeoxynucleotides (ODN) immunotherapy. This antibiotic-induced failure of immunotherapy response was due to a decrease of the gut microbiota load, leading to the decline of pro-inflammatory cytokines-producing monocytes in tumor (Figure 2) [10].

More recently, the impact of the gut microbiota on immune checkpoint inhibitor (ICI) therapy efficacy and toxicity has also been largely explored (Figure 2) [46-53]. Although the mechanisms are not well understood, these studies confirm the central role of remote lymphoid and myeloid cells modulation by the gut microbiota $[49,51,54,55]$. The first studies on ICI focused on sarcoma, melanoma and colon carcinoma murine models [46,47]. One of them showed that GF mice or antibiotic-treated mice were not capable to respond the cytotoxic T-lymphocyte antigen 4 (CTLA-4) inhibitor antibody compared to SPF mice [47]. Bacteroides thetaiotaomicron, Bacteroides fragilis and Burkholderia cepacia were isolated and associated with an effective response to anti-CTLA- 4 and with fewer side effects following therapy $[47,48]$. The restoration of the efficacy after oral feeding of mice with Bacteroides spp. was explained by an increase of intratumoral mature DCs with an elevation of Th1 response in tumor-draining lymph nodes. The impact of the microbiome was strongly reinforced by clinical studies which demonstrated that anti-CTLA-4 toxicity can be influenced by gut bacterial composition $[48,56]$. Another study highlighted that the response to anti-programmed death-ligand 1 (PD-L1) was dependent on the gut microbiota composition and particularly that Bifidobacterium spp. was linked to effective response to anti-PD-L1 (Figure 2) [46]. Bifidobacterium spp. administration in mice restored the efficacy of this ICI treatment by an increase of IFN- $\gamma^{+} \mathrm{CD} 8^{+} \mathrm{T}$-cells in tumor. Moreover, microbiota composition could predict the status of responder and non-responder patients to anti-programmed cell death 1 (PD-1)/PD-L1 therapy in solid epithelial tumors [49-52,57]. For example, Gopalakrishnan et al. [49] have shown enrichment of Faecalibacterium species in gut microbiome of melanoma patients responding to anti-PD-L1 while Bacteroides thetaiotaomicron, Escherichia coli, and Anaerotruncus colihominis were enriched in non-responders. Fecal Microbiota Transplantation (FMT) from responder patients into GF mice improved ICI efficiency. This effective response seems to be associated with a higher level of intratumoral mature DCs , IFN- $\gamma^{+} \mathrm{CD}^{+}$and/or $\mathrm{CD} 4^{+}$anti-tumor T cells and a lower amount of 
intratumoral CD4 ${ }^{+}$FoxP3 $^{+}$Tregs [49-52]. To demonstrate the role of microbiota on ICI efficacy in melanoma patients, a recent study highlighted that using antibiotics during the first 30 days of ICI therapy was associated with a shorter progression free survival compared to patients who did not receive antibiotherapy [58].

These promising results strongly support the inclusion of microbial targeting in anti-tumor immunotherapy strategies to enhance their efficacy, as reported in clinical trials. However, the clinical translation of microbiome effects on immunotherapy is limited by the fact that most preclinical studies have been conducted in mice carrying ectopic syngenic tumor that have already undergone a process of immune editing before transfer into their new host. These models cannot account for the constantly changing interactions between the immune system and tumors during the cancer elimination, equilibrium and escape stages. For a deeper comprehension of the underlying molecular mechanisms, humanized animal models or models of spontaneous tumorigenesis will probably be needed.
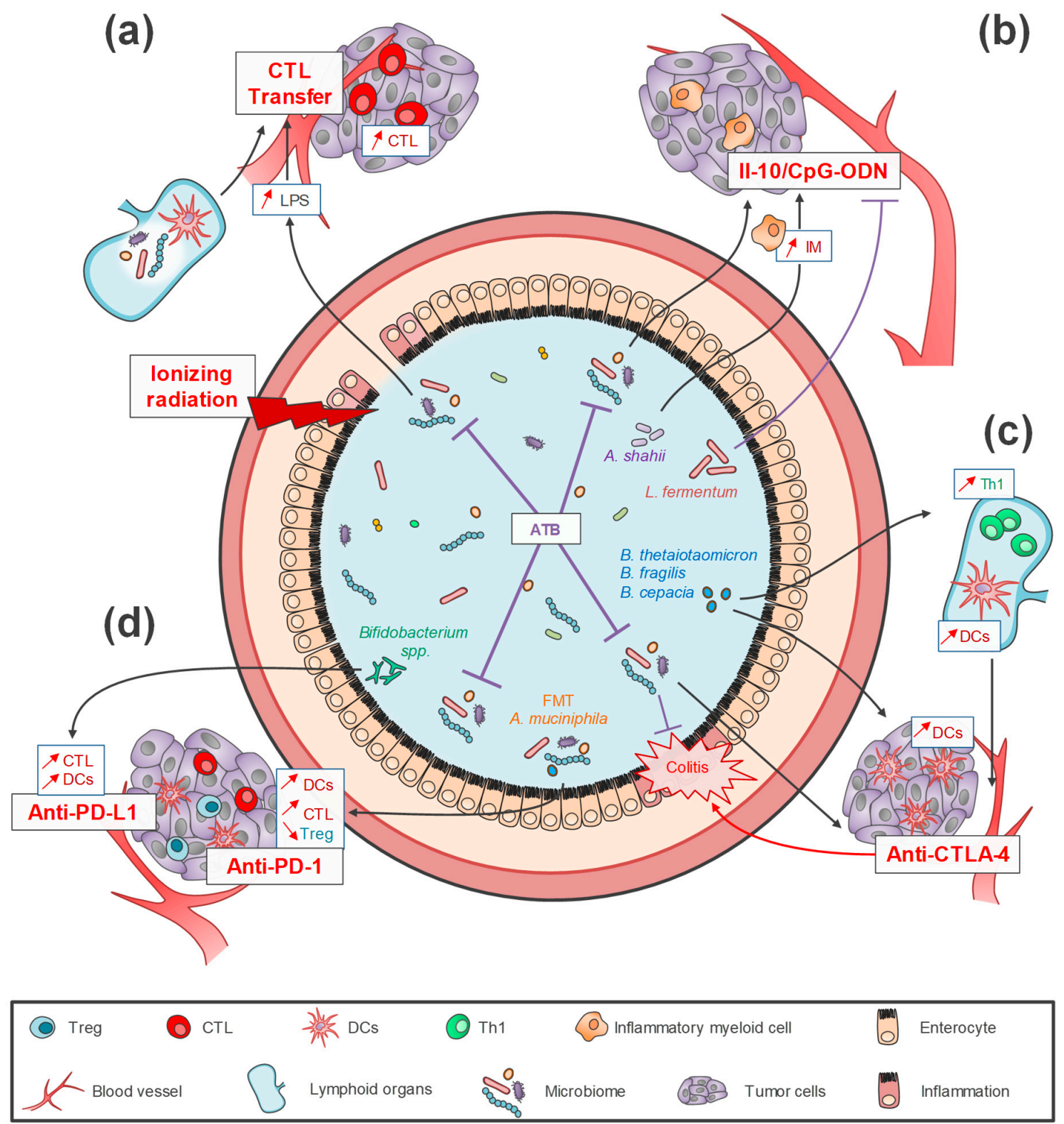

Figure 2. Impacts of intestinal microbiota on efficacy and toxicity of immunotherapy strategies. (a) Efficacy of anti-tumor CD8+ T cells (CTL) adoptive transfer (CTL transfer) has been stimulated by gut bacteria translocation into mesenteric lymph node and an increase of systemic LPS concentration induced by the total body irradiation in the murine model. This stimulation has been associated with 
an increase of CTL recruitment into a tumor microenvironment. (b) A decrease of gut bacterial load following antibiotics (ATB) therapy would impair the efficacy of anti-IL-10/CpG oligodeoxynucleotides (ODN) immunotherapy due to the decline of pro-inflammatory cytokine-producing myeloid cells (IM). In the same way, the negative role of Lactobacillus fermentum has been shown, meanwhile. A. shahii could increase the intratumoral IM and increase ODN efficacy $(\mathbf{c}, \mathbf{d})$ The impact of gut microbiota on ICI efficacy and toxicity via remoted lymphoid and myeloid cells modulation has been noticed. (c) Bacteroides thetaiotaomicron, Bacteroides fragilis and Burkholderia cepacia were associated with an increase of Th1 and dendritic cells (DCs) cells in lymphoid organs, leading to an increase in anti-CTLA-4 response. This microbiota-mediated immunotherapy response could be also supported by the recruitment of mature DCs in the tumor microenvironment. In addition, the presence of these specific bacteria could be associated with a decrease of anti-CTLA-4 side effects. (d) Bifidobacterium spp. was linked to effective anti-PD-L1 response due to the elevation of intratumoral CTL and DCs. The Fecal Microbiota Transplantation (FMT) from responder patients into GF mice could activate similar immune mechanism and improve the response to anti-PD-1 therapy in solid epithelial tumors. $(\mathbf{a}, \mathbf{b}, \mathbf{c}, \mathbf{d})$ ATB treatments have been reported to induce a decrease of anti-tumoral efficacy for all of these immunotherapies.

\subsection{Radiotherapy}

Radiotherapy is one of common treatments for patients with solid cancers. Ionizing radiation directly induces DNA damage by an energy transfer indirectly through the production of ROS or reactive nitrogen species (RNS) [59,60]. Moreover, radiotherapy can induce local immunogenic effects, such as immunogenic tumor cell death, activating local and systemic inflammation and modulating immunity [61]. Radiotherapy is also responsible of stimulation of the innate immune system. Barker et al. [62] underlined the triggering of a releasing of inflammatory cytokines such as IL- 1 and TNF- $\alpha$ and immune cell recruitment after treatment. However, tumor response after radiotherapy remains very heterogeneous, with significant differences from one patient to another and very variable oncologic outcomes. The cause of this heterogeneity remains unclear but recent data have suggested that tumor response could be affected by gut microbiota. The role of intestinal microbiota in radiosensitivity is a new concept generating a lot of interest but with still few original studies leading to convincing results [59]. Emerging preclinical studies performed on mouse models have tried to understand the link between gut microbiota and radioresistance. Cui et al. [63] investigated the effect of circadian rhythm on radiotherapy (with total body exposure) and compared it with the composition of the microbiota. They found that mice with normal 12-h dark/12-h light cycles had a significantly better survival than those with different cycles (8-h dark/16-h light or 16-h light/8-h dark). This was correlated to alterations in gut bacterial communities which could be part of the radioresistance mechanisms. The same team described a correlation between intestinal bacterial communities and radiosensitivity with an antibiotic-treated mouse model. The enteric bacterial composition of treated mice was significantly different from that of control group and the survival rate of antibiotic-treated mice was significantly higher after irradiation [64]. Another hypothesis concerns the link between radioresistance and autophagy regulation, which has already been suggested for nearly 20 years [65]. Digomann et al. [66] found that the expression level of some proteins involved in autophagy was correlated with the clinical prognosis of patients with head and neck squamous cell carcinoma treated with radiochemotherapy [67]. Gut microbiota is also involved in autophagy regulation. Indeed, as described above, the role of Fusobacterium nucleatum in chemoresistance through autophagy activation has been shown [41] (Figure 1). To date, no studies on the potential effect of gut microbiota composition on radiosensitivity through autophagy modulation have been published.

In addition, gut microbiota may affect radio-induced toxicity. Radiotherapy side effects alter quality of life and are an integral part of the treatment decision. For instance in pelvic cancer, in which radiotherapy is a major treatment, Ferreira et al. [68] showed, in a clinical study, a close link between gut microbiota composition and radiation enteropathy. Clostridium, Roseburia and Phascolarctobacterium abundance were significantly increased in patients with radiation enteropathy. Rectal Roseburia and 
Propionibacterium were inversely correlated with the rate of IL-15, which was decreased in patients with radiation enteropathy [69]. It is now accepted that ionizing radiation was responsible for microbiota dysbiosis in several pathologies as after pelvic radiation with radiation-induced bowel toxicity [68-71]. Another clinical study demonstrated a significant alteration of Firmicutes/Bacteroidetes ratio after pelvic radiation in patients who developed diarrhea [72]. All these studies led to the same conclusion: gut microbial dysbiosis could be a useful biological marker to predict and prevent radiation enteropathy or other complications $[68,69,72-74]$. This hypothesis has been confirmed in a mouse model. Fecal transplantation improved gastro-intestinal tract function in irradiated mice but also protected against radiation-induced death [64]. In addition, it was described in an animal model that neoadjuvant radiation could alter the phenotypic virulence of specific bacteria as Pseudomonas aeruginosa, leading to enhanced collagenase activity, junction disruption followed by epithelial cell death and complete monolayer destruction [75].

In conclusion, it is admitted that the intestinal microbiota could be a key player for the modulation of systemic immune response with radiosensitivity and radio-induced toxicity modulation [76]. However, the direct impact of gut microbiota on the efficacy of radiotherapy has not really been demonstrated yet [74]. Further preclinical and clinical studies are needed to identify the microbial populations involved in radioresistance and to make mechanistic assumptions.

\subsection{Surgery}

To our knowledge, the potential impact of gut microbiota on surgery outcomes has only been demonstrated in CRC, probably given the direct interaction between gut microbes and the resection site. The development of preventive strategies to decrease postoperative complications after colorectal surgery remains challenging for physicians treating patients with CRC [77-81]. In particular, anastomotic leaks (AL) are the most common life-threatening postoperative complication. Despite improvements in perioperative medical cares and many studies having been devoted to the technique or the anastomotic configuration, rates of AL have remained largely unchanged over the past decades, reported in $1 \%$ to $19 \%$ of patients [82-85]. A potential role of the gut microbiota in the pathogenesis of AL following colorectal surgery is now increasingly obvious [86-91]. Blain et al. reported that a parenteral administration of penicillin protected the ischemic bowel from necrosis, a broad spectrum antibiotic being even more protective [92]. The implication of the microbiome in AL was first suggested in the 1950s by Cohn et al., who reported a decrease in AL rates with the intraluminal administration of antibiotics in a dog model of devascularized colonic anastomosis, specifically at the anastomosis site [93]. Since, many studies have investigated the role of an oral antibiotic preparation in elective colorectal surgery and concluded that a potentially significant protective effect of postoperative complications existed, including AL [94]. However, microbial signatures associated with AL and involved mechanisms have been poorly studied. Recently, using 16S MiSeq sequencing on colorectal anastomosis tissue samples, van Praagh et al. reported that AL development was associated with low microbial diversity and correspondingly with a high abundance of the dominant Bacteroidaceae and Lachnospiraceae families and a low abundance of Prevotella oralis [95].

Following colorectal surgery, the restoration of the epithelial barrier integrity is one of the first and main events involved in anastomosis healing [96]. When impaired, underlying bowel tissue layers may be excessively exposed to detrimental intraluminal factors, such as bacteria, which can potentially compromise adequate anastomotic healing, potentially leading to the development of an AL [96]. Studies reported that environmental host signals, such as neoadjuvant therapies or surgery-induced stress, can lead to the activation of virulent bacteria responsible for tissue damages, thus supporting the potential role of gut microbiota alterations in the healing disorders of intestinal anastomoses $[97,98]$. Recently, Olivas et al. reported a significant increase in AL rates following radiation and low colonic anastomosis in rats inoculated with Pseudomonas aeruginosa, a ubiquitous hospital-associated pathogen and colonizer of hospitalized patients [75]. They also found that neoadjuvant radiation could alter the phenotypic virulence of specific bacteria, thus transforming inoculated Pseudomonas aeruginosa 
into a more invasive anastomotic-disrupting phenotype [75]. Moreover, they were able to prevent AL in radiated and inoculated tissue by blocking this transformation using a modified polyethylene glycol. The administration of butyrate enemas postoperatively after left-sided colectomy in a rat model also enhanced anastomotic healing by an increased collagen synthesis and maturation $[99,100]$, potentially due to an inhibition of these pathogenic Pseudomonas aeruginosa [101]. In another rat model of AL following low colonic resection, animals which developed AL on devascularized anastomoses were colonized at the anastomotic site by Enterococcus faecalis strains with a high collagenase activity, while healed anastomotic tissues were colonized by low collagenase-expressing Enterococcus faecalis [102]. These E. faecalis strains with a high collagenase activity were able to directly degrade collagen I and indirectly cleave collagen IV by activating host tissue matrix metalloproteinase 9 (MMP9). The inhibition of this collagenase activity, either by the colonic eradication of E. faecalis using the intraluminal administration of antibiotics or by the pharmacological suppression of the MMP9 collagenase activity, effectively prevented AL in devascularized anastomoses. Moreover, well vascularized anastomoses inoculated with high collagenase activity E. faecalis strains exhibited higher $\mathrm{AL}$ rates, similar to that of the devascularized anastomoses.

These findings definitely support the need for further clinical investigations on the host-microbiota interactions following colorectal surgery, and especially during the anastomotic healing process, to identify microbial signatures at risk for postoperative complications and to develop effective gut microbiota-targeted preventive strategies.

\section{Modulation of the Gut Microbiome to Enhance Therapy Efficacy: from Predictive Potential to Clinical Assays}

As described above, intestinal microbiota can provide novel way to enhance the efficacy and to reduce the side effects of current anti-tumoral therapeutic approaches. Several strategies can be considered in order to improve the efficacy of cancer treatment through gut microbiota modulation $[9,103,104]$. While targeting the gut microbiome has shown some interesting results in the treatment of cancers, the studies demonstrated that improved effects of cancer therapies following microbiota modulation are much more limited [105]. In this second part of the review, we focused on the potential strategies to optimize the microbiota composition in order improve therapy efficiency.

\subsection{Antibiotics}

Antibiotics are effective for treating various infections. Depending on their antimicrobial spectrum and pharmacokinetics, they can also change the composition of the gut microbiota. Antibiotics could be used to eliminate the bacteria that exert a negative effect on cancer therapy efficacy. However, the main issue with antibiotics is the lack of specificity, which in turn, can lead to a dysbiotic microbiota and induce detrimental health effects.

Several studies have assessed the role of an oral antibiotic preparation in elective colorectal surgery and concluded the presence of a potentially significant protective effect from postoperative complications. Rollins et al. compared the impact of the use of oral antibiotics in elective colorectal surgery in a meta-analysis of randomized controlled trials and cohort studies and showed a significant reduction of postoperative complications in patients treated with this therapeutic procedure [94].

Regarding the other types of cancer therapies, published studies have mainly evaluated the impact of antibiotics on ICI efficiency and showed that immunotherapy benefits may be attenuated by the administration of antibiotics $[48,51,58,106,107]$. A retrospective cohort study by Ahmed et al. [108] recently evaluated whether antibiotic use during anti-PD-1 therapy affected the treatment outcome of patients with cancer (lung, renal, hepatocellular, head and neck, melanoma, urothelial cancers, etc.). Among 60 patients with advanced cancer treated with ICI, 17 patients received antibiotics within 2 weeks before and/or after starting therapy because of diverse microbial infections. It is important to note that there was no statistical difference between the two groups in terms of PD-L1 expression. The study showed a lower response rate in patients who received systemic antibiotics 
within 2 weeks before or after the first dose of therapy when compared to those who did not. The authors defined the types of antibiotic as follows: narrow spectrum only covers Gram-positive bacteria, while broad-spectrum antibiotics cover Gram-positive and negative bacteria, both aerobic and anaerobic. They reported that patients treated with broad-spectrum antibiotics experienced a lowered response rate in contrast to patients treated with narrow spectrum antibiotics. Overall, patients who did not received broad-spectrum antibiotics enjoyed a longer overall survival compared to those who did [108]. On the contrary, in a retrospective cohort study with 90 patients treated with PD-1 ICI (Nivolumab) for non-small cell lung cancer, Hakozaki et al. [109] reported no significant effect of antibiotic use prior to immunotherapy. However, only 13 patients among the cohort received antibiotics and the results showed a trend toward a negative influence of antibiotic use. The authors suggested that the timing between the treatment with antibiotic and the beginning of Nivolumab therapy might play an important role. Indeed, the microbiota composition can drastically change following the discontinuation of antibiotics [110]. Still, for advanced non-small cell lung cancer, Huemer et al. [106] evaluated the impact of concomitant administration of antibiotics in temporal proximity to initiation of immune-checkpoint inhibitors therapy (one month before or one month after initiation), and their results showed that antibiotics attenuated the benefits of immune-checkpoint inhibitors. However, in their study, Vétizou et al. [47] reported an enhanced effect of CTLA-4 blockade in mice administered with vancomycin, probably because the antibiotic induced the overrepresentation of gram-negative Bacteroidales and Burkholderiales at the expense of gram-positive bacteria such as Clostridiales.

Due to a lack of specificity and the induction of a dysbiosis, more investigations are required to reduce the impact of antibiotic use during cancer treatment. Promising perspectives for probiotic co-administration during antibiotic therapy need to be addressed (see below). As an alternative, highly specific strategies such as phagotherapy could be considered to target some gut bacteria. In addition regarding CRC, a preclinical study has demonstrated the efficacy of pro-carcinogenic bacterial-toxin-targeting using small molecules, suggesting the interest of this innovative concept [111].

\subsection{Fecal Microbiota Transplantation (FMT)}

Fecal transplants come with a lot of unknowns, and given the uncertainties, some scientists argue that testing these approaches in humans is risky. FMT has been widely used in the treatment of resistant Clostridium difficile infection with high response rates [112], giving promising perspectives for other pathologies. However, FMT data in the context of cancer therapy are much more limited and data have been mainly obtained on animal models.

Since recent clinical papers suggested a potential involvement of the gut microbiome in influencing the efficacy of both CTLA-4- and PD-1-targeting checkpoint inhibitors [49-51], the authors of these publications collected the fecal specimens to characterize the mechanisms involved in resistance of immunotherapy on rodent tumor models. Gopalakrishnan et al. [49] orally transferred the fecal microbiota of responder or non-responder patients to anti-PD-1 therapy into melanoma-bearing GF mice. At day 28 post-tumor inoculation and after treatment, responder patient FMT-treated mice had one-sixth the tumor volume of non-responder patient FMT treated mice. In the same way, Matson et al. [50] transferred the fecal material from three human responders and three non-responders from their study into GF mice, followed by the implantation of melanoma cells. They observed two phenotypes of human-microbiota-colonized mice: one with a fast tumoral growth rate, which included two of the three mouse cohorts reconstituted with fecal material from non-responding patients to anti-PD-1, and one with a slower growing rate, including two of the three mouse cohorts reconstituted with fecal material from responding patients [50].

After showing that antibiotics compromised the therapeutic efficacy of ICI in mice and in cancer patients, Routy et al. [51] recolonized antibiotic-treated mice with fecal microbiota from 4 responding and 4 non-responding patients to therapy. Stool samples from clinical responders conferred sensitivity, whereas those from non-responding patients conveyed resistance to PD-1 blockade. The authors observed that FMT from responding patients but not from non-responding patients into GF mice 
caused tumor growth delay, accumulation of $\mathrm{CXCR} 3{ }^{+} \mathrm{CD}^{+} \mathrm{T}$ cells in the tumor microenvironment, and up-regulation of PD-L1 in splenic T cells after PD-1 blockade. Taken together, these results suggest that manipulating the gut microbiota of patients could influence the outcome of ICI, but trials on patients are necessary to confirm these results.

Several clinical trials incorporating FMT in order to improve cancer therapy are still ongoing [103]. A clinical trial led by Dr. Davar (NCT03341143) is currently assessing the effect of FMT in 20 patients with advanced metastatic melanoma who have undergone treatment with pembrolizumab (anti-PD-1) and have failed or become nonresponsive to the therapy during their treatment. They received a fecal microbiota transplant from patients who had proven to be long-term responders to pembrolizumab, in combination with pembrolizumab treatment. Another clinical trial on 40 melanoma patients who failed immunotherapy by PD-1 blockade started in 2017, led by Dr. Markel (NCT03353402). This study aims to change the gut microbiota of patients with fecal transplants from donors who responded to immunotherapy. However, this trial does not combine FMT with the immunotherapy treatment for which patients were nonresponsive. Other trials using FMT are currently in progress to reduce the adverse effects of anticancer treatments (NCT02928523. Although the clinical relevance of FMT seems promising, leaders in the field are still cautious regarding these trials and are looking for standardized approaches.

\subsection{Probiotics and Prebiotics}

\subsubsection{Probiotics}

The concept of probiotic proposed by Metchnikoff and defined by the Food and Agriculture Organization/World Health Organization (FAO/WHO) as "live microorganisms which when administered in adequate amounts confer a health benefit on the host" $[113,114]$, has become an important research field [115]. A recent meta-analysis assessing the efficacy and safety of probiotics in adult and pediatric patients diagnosed with cancer suggests that probiotics may be beneficial, even if the mechanisms underlying antitumor properties remain unclear and further studies are still required [116]. However, although most studies have focused on the effect of probiotics on tumorigenesis inhibition or on cancer therapy-related toxicity [117], only a few studies have assessed the potential of probiotics to enhance the efficiency of cancer treatments [118].

In 1993, a phase III multicentered randomized controlled study on 223 patients with carcinoma of the uterine cervix showed that combining treatment with heat-killed Lactobacillus casei strains (LC9018) and radiation therapy enhanced tumor regression through the induction of immune response against cancer cells [119]. Since then, the potential applications of the combination probiotics/cancer treatment have sparked interest for future studies. Indeed, gut microbiota seem to regulate the and the repair of irradiation-induced damages [12]. Ciorba et al. [120] have shown that the probiotic strain Lactobacillus rhamnosus GG (LGG) protected the mouse intestinal mucosa against irradiation-related toxicity by driving the repositioning of cyclooxygenase 2-expressing cells.

In a double-blind placebo-controlled trial including 490 patients, the probiotic preparation VSL\#3, which includes eight strains of lactic acid-producing bacteria (Streptococcus thermophilus, Bifidobacterium breve, Bifidobacterium longum, Bifidobacterium infantis, Lactobacillus acidophilus, Lactobacillus plantarum, Lactobacillus paracasei, Lactobacillus delbrueckii subsp. Bulgaricus), protected the patients against radiation-induced diarrhea [121]. In line with these studies, a number of ongoing clinical trials currently focus on establishing the role of probiotics administration in preventing or limiting the toxic effects of anticancer therapies [104]. However, most of these studies are focused on reducing the radiation-related side effects, but do not investigate the direct impact of probiotics on therapy efficiency. In a clinical randomized control study, patients treated for a nasopharyngeal carcinoma had an enhanced immune response and a decreased rate of radiation toxicities (oral mucositis) after chemoradiotherapy when they received a combination of probiotics to prevent dysbiosis. Indeed, the probiotic combination increased the number of $\mathrm{CD} 4^{+} \mathrm{T}$ cells, $\mathrm{CD} 8^{+} \mathrm{T}$ cells and $\mathrm{CD}^{+} \mathrm{T}$ cells and the incidence of severe 
grade of oral mucositis was significantly decreased in patients treated with probiotics [122]. It should be noted that recently, a study by Wang et al. [73] showed that administration of the probiotic strain Lactobacillus reuteri inhibited the development and progression of ICI therapy-associated colitis in melanoma tumor-bearing mice without affecting the antitumor effect of the immunotherapy.

Regarding chemotherapy, a study by Viaud et al. [11] on tumor-bearing mice focused on the role played by the gut microbiota on CTX treatment. The authors observed a disruption of gut mucosal integrity associated with dysbiosis in CTX-treated animals. While they found an impaired tumor regression in GF mice and in antibiotic-treated mice concomitantly to a reduced CTX-induced Th17 cell conversion, an oral supplementation with Enterococcus hirae and Lactobacillus johnsonii in antibiotic-treated mice facilitated the restoration CTX-mediated Th17 cell conversion [11]. More recently, the same group showed that oral administration of Enterococcus hirae in antibiotic-treated sarcoma-bearing mice restored the CTX anti-tumor efficacy by inducing an improved $\mathrm{T}$ cell immune response, as described previously [32]. Altogether, the results of these studies highlight specific commensal strains that could be used as probiotics in combination with CTX therapy to improve treatment efficacy in cancer patients. Concerning immunotherapy, a handful of strains correlating to checkpoint inhibitor efficiency have been tested in GF or SPF animal models of cancer [57]. In 2013, lida et al. [10] showed that an oral administration of Alistipes shahii in mice pre-exposed to antibiotics restored the ability of tumor-associated myeloid cells to produce TNF in animals treated with anti-IL-10R/CpG-ODN therapy. As reported by Sivan et al. [46] in a mouse model of cutaneous melanoma, Bifidobacterium were associated with slow tumor growth and beneficial responses to anti-PD-L1 therapy. Oral administration of probiotics containing Bifidobacterium to mice harbouring unfavorable gut microbiota increased the anti-tumor efficacy of PD-L1 blockade and nearly abolished tumor growth [46]. In 2015, Vétizou et al. [47] compared the efficacy of anti-CTLA-4 antibody treatment in SPF, antibiotic-treated or GF mice with established ectopic tumors. The treatment had no effect on GF or antibiotic-treated mice when compared to SPF mice. The authors found that the administration of anti-CTLA-4 therapy to SPF mice reduced the relative abundance of Bacteroidales and Burkholderiales. They also reported that GF and antibiotic-treated mice orally fed Bacteroides fragilis, Bacteroides thetaiotaomicron, Burkholderia cepacia or a combination of Bacteroides fragilis and Burkholderia cepacia recovered from the anticancer response to CTLA-4 antibodies. Vétizou et al. confirmed the clinical relevance of their findings by identifying patients with microbiome composed by a large proportion of Bacteroides species and observed that the prevalence of patients with this microbial composition increased following treatment. As underlined by Bashiardes et al. [9], both studies used the same mouse tumor model but identified different bacterial strains that improved therapeutic response, possibly because they used different ICIs or because of distinct mice microbiota. Finally, Tanoue et al. [52] recently isolated 11 commensal strains from healthy human donor feces that are strong inducers of interferon- $\gamma$-producing CD8 T cells in the intestine of GF mice. These strains (Ruthenibacterium lactatiformans, Eubacterium limosum, Fusobacterium ulcerans, Phascolarctobacterium succinatutens, Bacteroides uniformis, Bacteroides dorei, Paraprevotella xylaniphila, Parabacteroides distasonis, Parabacteroides johnsonii, Parabacteroides gordonii, and Alistipes senegalensis) represent rare low-abundance components of the human microbiome. In MC38 tumor-bearing SPF mice, response to anti-PD-1 or anti-CTLA-4 antibodies was significantly enhanced in animal colonized with the 11 strains. These translational studies suggest that bacteria administration may enhance immune-checkpoint inhibitor therapy and chemotherapy efficacy in several rodent tumor models through the stimulation of dendritic cells to secrete IL-12 and differentiate tumor cytotoxic T lymphocytes [57].

Several clinical trials targeting the gut microbiota with probiotic strains to improve anticancer therapy efficacy are ongoing. In 2012, a randomized, double-blind, placebo-controlled phase III study involving 160 patients in Italy with rectal cancer has been designed to assess the efficacy of the probiotic preparation VSL\#3@in increasing the pathological major response rate in patients undergoing concurrent chemotherapy and pelvic radiotherapy, but to our knowledge, no data have been published (NCT01579591). Another ongoing study on 20 breast cancer patients that are given 
Primal Defense Ultra®Probiotic Formula (Saccharomyces boulardii, Lactobacillus plantarum, Bacillus subtilis, Bifidobacterium lactis, Bifidobacterium bifidum, Lactobacillus rhamnosus, Bifidobacterium breve, Lactobacillus casei, Lactobacillus salivarius, Lactobacillus acidophilus, Lactobacillus brevis, Bifidobacterium longum, and Lactobacillus paracasei) 2-4 weeks 3 times a day prior to surgery aims to evaluate the efficacy of presurgical probiotics to influence antitumor immune function (NCT03358511). A phase IV randomized clinical study led by Dr. Correia and completed in 2016 (NCT01609660) showed that daily oral supplementation with Saccharomyces boulardii for seven days prior to colorectal resection in CRC patients led to a reduction of inflammatory cytokines in the colonic mucosa without affecting the postoperative infection rates [123]. A clinical trial targeting the gut microbiota with a probiotic to improve immune-checkpoint inhibitor efficiency is currently ongoing. This phase I trial aims to evaluate the effect of the probiotic Clostridium butyricum CBM588 strain in combination with Nivolumab and Ipilimumab in treating patients with kidney cancer (NCT03829111). In 2019, a trial aiming to compare the effect of chemotherapy on the survival of patients treated for metastatic CRC and that receive or not a probiotic preparation of Weileshu $囚$, but the trial is not yet recruiting (NCT04021589).

Taken together, all these data give crucial information regarding the potential strains to use in order to improve anticancer-therapy efficacy. However, a deeper understanding of the molecular mechanisms underlying single commensal/probiotic strains effects seems to be the next step to optimize probiotic use in association with cancer treatment.

\subsubsection{Prebiotics and Synbiotics}

Many food components act as the actual food for gut bacteria which can metabolize those into tumor suppressive metabolites [124]. The use of prebiotics, known as dietary fibers non-digestible or absorbable by the host and specifically used by gut microbes [125], should increase the colonization and relative expansion of particular bacteria and their specific metabolites, which may have a beneficial effect on anti-tumor treatment. However, the potential effect of prebiotics depends on the presence of beneficial bacteria already in the host gut. Thus, the combination of probiotics and prebiotics, known as synbiotic, seems promising.

As described above, a low diversity of the gut microbiome has been independently associated with poor response to immunotherapy in advanced melanoma patients [49], but also with poor outcomes in patients undergoing allogeneic stem cell transplant [126]. In this context, pre- and synbiotic therapy could be considered prior to and along-side therapy to maintain diversity and improve efficacy [8]. To our knowledge, there is only one published study addressing the question of prebiotic or synbiotic in the improvement of cancer treatment efficacy. Indeed, a Brazilian group evaluated the effect of synbiotics in patients with periampullary cancers undergoing curative or palliative treatment by assessing mortality and postoperative infections (NCT0146877). The data published showed a reduced postoperative mortality and complication rates in patients treated pre- and post-surgery with a mixture including Lactobacillus acidophilus, Lactobacillus rhamnosus, Lactobacillus casei and Bifidobacterium bifidum combined with fructooligosaccharides [127]. Moreover, a phase II randomized study started in 2019 aims to investigate the effect of probiotics and prebiotics during the definitive treatment of chemotherapy-radiotherapy for patients with localized anal canal squamous cell cancer to improve treatment effectiveness and clinical outcomes (NCT03870607). Prebiotics or synbiotics might improve oncological outcomes in patients, thus allowing the development of new approaches to increase anticancer therapy efficiency.

\subsection{Physical Activity}

Increasing data also suggest the key role of lifestyle on cancer prognosis, more specifically in CRC patients [128]. Dysbiosis could affect the integrity of skeletal muscle, leading to muscle atrophy [129-132]. The latter is a key player of morbidity and mortality in various cancer entities [133-137] and an important predictor of overall survival in patients, including CRC [138]. The assumption of a new inter-organ cross-talk, 'gut microbiota-skeletal muscle' axis, has recently 
emerged [129]. Indeed, the restoration of commensal E. coli levels in a murine model of intestinal chronic inflammation could prevent muscle atrophy [139]. Moreover, the use of a synbiotic treatment in order to restore a "healthy" microbiota has reduced the proliferation of cancer and muscle cachexia and prolonged the survival of mice [7]. For example, restoration of lactobacilli levels counteracted muscle atrophy and decreased systemic inflammation in preclinical models of cancer cachexia $[140,141]$. These models are characterized by a common microbial signature resulting mainly in an increase in Enterobacteriaceae species [142,143], specifically Klebsiella oxytoca and in a reduction in three butyrate-producing microbial families (Ruminococcaceae, Lachnospiraceae and Porphyromonadaceae) [144]. Taken together, these preclinical data support that the gut microbiota could be the key player in the intestine-skeletal muscle interconnection and thereby contribute to muscle atrophy in cancer. However, gut microbiota in cancer patients with and without cachexia remains to be explore to reinforce the potential interest of 'gut microbiota-skeletal muscle' axis in the care of cancer patients.

Among complementary therapeutic perspectives, physical activity (PA) emerges as an original and promising approach in cancer context. PA seems to have a significant beneficial impact in terms of diagnosis, recurrence, mortality, therapeutic efficacy, and cancer- and treatment-related adverse effects (cachexia, depression, anxiety, and cognitive problems) [145-150]. Specifically for CRC, several observational and experimental studies conducted have recommended exercise as an effective method to prevent CRC and improve the negative effects of cancer and its treatment [151,152]. However, the molecular mechanisms underlying the protective effect of exercise regarding cancer have not yet been defined. The benefit of exercise could be related to its impact on metabolic and/or hormonal dysregulations, adiposity, oxidative stress, inflammation and/or immune impairment, transcriptional misregulation, and mitochondrial dysfunction [128,150,151]. In addition, several studies have indicated that exercise could also modulate the tumor physiologic microenvironment and improve antitumor immunity $[153,154]$. Taken together, these effects of exercise could have a favorable and lasting impact on tumor growth kinetics and metabolism $[155,156]$. In addition, other suggested mechanisms could also underly the effects of exercise on tumorigenesis, particularly in the CRC context, such as the modulatory effect of PA on colon transit time [157] and on intestinal microbiota [158]. The impact of PA on gut microbiota has not been widely studied in the literature. For instance, preclinical data showed that several weeks of running induced changes in the microbiota of rodents, depending on exercise modalities [159-164]. For example, in preliminary preclinical results of Maillard et al. [159], spontaneous regular PA led to a significant decrease in mesenteric adipose tissue in a murine model, mimicking susceptibility to intestinal inflammation and associated with a change in beta diversity of the microbiota associated with the intestinal mucosa. In elite athletes, the levels of PA were correlated with gut microbial features (composition and functional microbial characteristics), including an increase of $\alpha$-diversity, short-chain fatty acids production, and microbial metabolic capacity [165-167]. The impact of PA on gut microbiota was also suggested by Cronin et al. [168] in sedentary healthy subjects in whom the establishment of a controlled PA led changes in gut microbiota characteristics. However, the impact of PA on gut microbiota in severe pathological contexts such as cancer remains an unexplored topic, especially regarding its potential benefit in reducing the negative effects of both cancer and its treatment. This is one of the goals of the single-blinded randomized controlled trial of Newton et al. [169] designed to measure the impact of a supervised exercise program on gut microbiota and its metabolome in patients with prostate cancer receiving androgen deprivation therapy.

Considering the potential importance of 'gut microbiota-skeletal muscle' axis, the modulation of microbiota by PA could be an innovative idea with significant scientific and socioeconomic impacts. These interactions remain to be explored in the cancer context to reinforce the potential interest of PA in the care of cancer patients.

\section{Conclusions \& Prospects}

An increased number of studies have recently highlighted the key role of the gut microbiome to fight cancers by modulating the efficacy of cancer therapies and their side effects. A deep understanding 
of the complex interactions between host response and the microbiota appears certainly essential, but also provide promising tools to optimize the use of anticancer drugs through the modulation of the microbiome. Although all underlying mechanisms have not been well identified, promising tools will be developed to optimize therapeutic decisions by using intestinal microbiota composition as a prognostic factor in cancers $[49,170-173]$. These approaches will, of course, require fast, robust and inexpensive screening methods to assess microbiome composition of patients. Eventually, interventional strategies could be set up to ensure that patients have a favorable gut microbiota and a competent immune system at the onset of and all along, a personalized cancer therapy. In conclusion, intestinal microbiota undoubtedly constitutes a new promising lever for the scientific and clinical communities to improve the efficacy of anticancer therapies not only in digestive tract neoplasia but also in all the other tissues.

Funding: This research was funded by the Ministère de la Recherche et de la Technologie, Inserm and Université Clermont-Auvergne (UMR1071), INRA (USC-2018) and by la Ligue Contre le Cancer and by the French government IDEX-ISITE initiative (Grant number: 16-IDEX-0001-CAP 20-25) of the University of Clermont Auvergne. A.L. and R.V. were supported by a CIFRE grant (Grant number: 2015/622) and by a CPER EPICURE 2016 grant respectively.

Conflicts of Interest: The authors declare no conflict of interest.

\section{Abbreviations}

\begin{tabular}{|c|c|}
\hline $\mathrm{AL}$ & Anastomotic leaks \\
\hline ATB & Antibiotic \\
\hline$\beta$-gluc-PB & $\beta$-glucuronidase-producing bacteria \\
\hline BIRC3 & Baculoviral IAP Repeat Containing 3 \\
\hline BVU & 5-(2-bromovinyl)uracil \\
\hline CRC & Colorectal cancer \\
\hline CTLA-4 & Cytotoxic T-lymphocyte-associated protein 4 \\
\hline CTX & Cyclophosphamide \\
\hline DCs & Dentritic cells \\
\hline $\mathrm{FAO} / \mathrm{WHO}$ & Food and Agriculture Organization/World Health Organization \\
\hline FMT & Fecal Microbiota Transplantation \\
\hline GTB & Gemcitabine \\
\hline GF & Germ-free \\
\hline ICI & Immune checkpoint inhibitor \\
\hline IL & Interleukin \\
\hline LGG & Lactobacillus rhamnosus GG \\
\hline LPS & Lipopolysaccharides \\
\hline MMP & Metalloproteinase \\
\hline$N F-\kappa B$ & Nuclear factor-kappa B \\
\hline ODN & oligodeoxynucleotides \\
\hline OXA & Oxaliplatin \\
\hline PA & Physical activity \\
\hline PD-1 & Programmed cell death 1 \\
\hline PD-L1 & Programmed death-ligand 1 \\
\hline RNS & Reactive nitrogen species \\
\hline ROS & Reactive oxygen species \\
\hline SPF & Specific Pathogen Free \\
\hline $\mathrm{Tc}$ & Cytotoxic T cell \\
\hline Th & $\mathrm{T}$ helper cell \\
\hline TILs & Tumor infiltrating-lymphocytes \\
\hline TLR & Toll-like-receptor \\
\hline TNF & Tumor Necrosis Factor \\
\hline Treg & Regulatory T cell \\
\hline 5-FU & 5- fluorouracil \\
\hline
\end{tabular}




\section{References}

1. Collins, D.; Hogan, A.M.; Winter, D.C. Microbial and viral pathogens in colorectal cancer. Lancet Oncol. 2011, 12, 504-512. [CrossRef]

2. Zhang, Y.-J.; Li, S.; Gan, R.-Y.; Zhou, T.; Xu, D.-P.; Li, H.-B. Impacts of Gut Bacteria on Human Health and Diseases. Int. J. Mol. Sci. 2015, 16, 7493-7519. [CrossRef] [PubMed]

3. Lin, L.; Zhang, J. Role of intestinal microbiota and metabolites on gut homeostasis and human diseases. BMC Immunol. 2017, 18, 2. [CrossRef] [PubMed]

4. Schwabe, R.F.; Jobin, C. The microbiome and cancer. Nat. Rev. Cancer 2013, 13, 800-812. [CrossRef] [PubMed]

5. Elinav, E.; Garrett, W.S.; Trinchieri, G.; Wargo, J. The cancer microbiome. Nat. Rev. Cancer 2019, 19, 371-376. [CrossRef] [PubMed]

6. Whisner, C.M.; Athena Aktipis, C. The Role of the Microbiome in Cancer Initiation and Progression: How Microbes and Cancer Cells Utilize Excess Energy and Promote One Another's Growth. Curr. Nutr. Rep. 2019, 8, 42-51. [CrossRef]

7. Zitvogel, L.; Daillère, R.; Roberti, M.P.; Routy, B.; Kroemer, G. Anticancer effects of the microbiome and its products. Nat. Rev. Microbiol. 2017, 15, 465-478. [CrossRef] [PubMed]

8. Scott, A.J.; Merrifield, C.A.; Younes, J.A.; Pekelharing, E.P. Pre-, pro- and synbiotics in cancer prevention and treatment-A review of basic and clinical research. Ecancermedicalscience 2018, 12. [CrossRef] [PubMed]

9. Bashiardes, S.; Tuganbaev, T.; Federici, S.; Elinav, E. The microbiome in anti-cancer therapy. Semin. Immunol. 2017, 32, 74-81. [CrossRef]

10. Iida, N.; Dzutsev, A.; Stewart, C.A.; Smith, L.; Bouladoux, N.; Weingarten, R.A.; Molina, D.A.; Salcedo, R.; Back, T.; Cramer, S.; et al. Commensal Bacteria Control Cancer Response to Therapy by Modulating the Tumor Microenvironment. Science 2013, 342, 967-970. [CrossRef]

11. Viaud, S.; Saccheri, F.; Mignot, G.; Yamazaki, T.; Daillere, R.; Hannani, D.; Enot, D.P.; Pfirschke, C.; Engblom, C.; Pittet, M.J.; et al. The Intestinal Microbiota Modulates the Anticancer Immune Effects of Cyclophosphamide. Science 2013, 342, 971-976. [CrossRef] [PubMed]

12. Ma, W.; Mao, Q.; Xia, W.; Dong, G.; Yu, C.; Jiang, F. Gut Microbiota Shapes the Efficiency of Cancer Therapy. Front. Microbiol. 2019, 10. [CrossRef] [PubMed]

13. Alexander, J.L.; Wilson, I.D.; Teare, J.; Marchesi, J.R.; Nicholson, J.K.; Kinross, J.M. Gut microbiota modulation of chemotherapy efficacy and toxicity. Nat. Rev. Gastroenterol. Hepatol. 2017, 14, 356-365. [CrossRef] [PubMed]

14. Guthrie, L.; Gupta, S.; Daily, J.; Kelly, L. Human microbiome signatures of differential colorectal cancer drug metabolism. NPJ Biofilms Microbiomes 2017, 3, 27. [CrossRef] [PubMed]

15. Nakayama, H.; Kinouchi, T.; Kataoka, K.; Akimoto, S.; Matsuda, Y.; Ohnishi, Y. Intestinal anaerobic bacteria hydrolyse sorivudine, producing the high blood concentration of 5-(E)-(2-bromovinyl)uracil that increases the level and toxicity of 5-fluorouracil. Pharmacogenetics 1997, 7, 35-43. [CrossRef] [PubMed]

16. Wallace, B.D.; Wang, H.; Lane, K.T.; Scott, J.E.; Orans, J.; Koo, J.S.; Venkatesh, M.; Jobin, C.; Yeh, L.-A.; Mani, S.; et al. Alleviating Cancer Drug Toxicity by Inhibiting a Bacterial Enzyme. Science 2010, 330, 831-835. [CrossRef] [PubMed]

17. Wang, J.; Feng, W.; Zhang, S.; Chen, L.; Tang, F.; Sheng, Y.; Ao, H.; Peng, C. Gut microbial modulation in the treatment of chemotherapy-induced diarrhea with Shenzhu Capsule. BMC Complement. Altern. Med. 2019, 19, 126. [CrossRef] [PubMed]

18. Diasio, R.B. Sorivudine and 5-fluorouracil; a clinically significant drug-drug interaction due to inhibition of dihydropyrimidine dehydrogenase. Br. J. Clin. Pharmacol. 1998, 46, 1-4. [CrossRef] [PubMed]

19. Brandi, G.; Dabard, J.; Raibaud, P.; Di Battista, M.; Bridonneau, C.; Pisi, A.M.; Morselli Labate, A.M.; Pantaleo, M.A.; De Vivo, A.; Biasco, G. Intestinal microflora and digestive toxicity of irinotecan in mice. Clin. Cancer Res. Off. J. Am. Assoc. Cancer Res. 2006, 12, 1299-1307. [CrossRef]

20. Stringer, A.M.; Gibson, R.J.; Logan, R.M.; Bowen, J.M.; Yeoh, A.S.J.; Hamilton, J.; Keefe, D.M.K. Gastrointestinal microflora and mucins may play a critical role in the development of 5-Fluorouracil-induced gastrointestinal mucositis. Exp. Biol. Med. Maywood NJ 2009, 234, 430-441. [CrossRef]

21. Rigby, R.J.; Carr, J.; Orgel, K.; King, S.L.; Lund, P.K.; Dekaney, C.M. Intestinal bacteria are necessary for doxorubicin-induced intestinal damage but not for doxorubicin-induced apoptosis. Gut Microbes 2016, 7, 414-423. [CrossRef] [PubMed] 
22. Stringer, A.M.; Gibson, R.J.; Bowen, J.M.; Logan, R.M.; Ashton, K.; Yeoh, A.S.J.; Al-Dasooqi, N.; Keefe, D.M.K. Irinotecan-induced mucositis manifesting as diarrhoea corresponds with an amended intestinal flora and mucin profile. Int. J. Exp. Pathol. 2009, 90, 489-499. [CrossRef] [PubMed]

23. Fijlstra, M.; Ferdous, M.; Koning, A.M.; Rings, E.H.H.M.; Harmsen, H.J.M.; Tissing, W.J.E. Substantial decreases in the number and diversity of microbiota during chemotherapy-induced gastrointestinal mucositis in a rat model. Support. Care Cancer 2015, 23, 1513-1522. [CrossRef] [PubMed]

24. Hong, B.-Y.; Sobue, T.; Choquette, L.; Dupuy, A.K.; Thompson, A.; Burleson, J.A.; Salner, A.L.; Schauer, P.K.; Joshi, P.; Fox, E.; et al. Chemotherapy-induced oral mucositis is associated with detrimental bacterial dysbiosis. Microbiome 2019, 7, 66. [CrossRef] [PubMed]

25. Montassier, E.; Gastinne, T.; Vangay, P.; Al-Ghalith, G.A.; Bruley des Varannes, S.; Massart, S.; Moreau, P.; Potel, G.; de La Cochetière, M.F.; Batard, E.; et al. Chemotherapy-driven dysbiosis in the intestinal microbiome. Aliment. Pharmacol. Ther. 2015, 42,515-528. [CrossRef]

26. Montassier, E.; Batard, E.; Massart, S.; Gastinne, T.; Carton, T.; Caillon, J.; Le Fresne, S.; Caroff, N.; Hardouin, J.B.; Moreau, P.; et al. 16S rRNA gene pyrosequencing reveals shift in patient faecal microbiota during high-dose chemotherapy as conditioning regimen for bone marrow transplantation. Microb. Ecol. 2014, 67, 690-699. [CrossRef] [PubMed]

27. Rooks, M.G.; Veiga, P.; Wardwell-Scott, L.H.; Tickle, T.; Segata, N.; Michaud, M.; Gallini, C.A.; Beal, C.; van Hylckama-Vlieg, J.E.T.; Ballal, S.A.; et al. Gut microbiome composition and function in experimental colitis during active disease and treatment-induced remission. ISME J. 2014, 8, 1403-1417. [CrossRef]

28. Van Vliet, M.J.; Tissing, W.J.E.; Dun, C.A.J.; Meessen, N.E.L.; Kamps, W.A.; de Bont, E.S.J.M.; Harmsen, H.J.M. Chemotherapy treatment in pediatric patients with acute myeloid leukemia receiving antimicrobial prophylaxis leads to a relative increase of colonization with potentially pathogenic bacteria in the gut. Clin. Infect. Dis. 2009, 49, 262-270. [CrossRef]

29. Wang, Y.; Sun, L.; Chen, S.; Guo, S.; Yue, T.; Hou, Q.; Feng, M.; Xu, H.; Liu, Y.; Wang, P.; et al. The administration of Escherichia coli Nissle 1917 ameliorates irinotecan-induced intestinal barrier dysfunction and gut microbial dysbiosis in mice. Life Sci. 2019, 231, 116529. [CrossRef]

30. Liu, T.; Wu, Y.; Wang, L.; Pang, X.; Zhao, L.; Yuan, H.; Zhang, C. A More Robust Gut Microbiota in Calorie-Restricted Mice Is Associated with Attenuated Intestinal Injury Caused by the Chemotherapy Drug Cyclophosphamide. mBio 2019, 10, e02903-18. [CrossRef]

31. Reyna-Figueroa, J.; Barrón-Calvillo, E.; García-Parra, C.; Galindo-Delgado, P.; Contreras-Ochoa, C.; Lagunas-Martínez, A.; Campos-Romero, F.H.; Silva-Estrada, J.A.; Limón-Rojas, A.E. Probiotic Supplementation Decreases Chemotherapy-induced Gastrointestinal Side Effects in Patients With Acute Leukemia. J. Pediatr. Hematol. Oncol. 2019, 41, 468-472. [CrossRef]

32. Daillère, R.; Vétizou, M.; Waldschmitt, N.; Yamazaki, T.; Isnard, C.; Poirier-Colame, V.; Duong, C.P.M.; Flament, C.; Lepage, P.; Roberti, M.P.; et al. Enterococcus hirae and Barnesiella intestinihominis Facilitate Cyclophosphamide-Induced Therapeutic Immunomodulatory Effects. Immunity 2016, 45, 931-943. [CrossRef]

33. Kuczma, M.P.; Ding, Z.-C.; Li, T.; Habtetsion, T.; Chen, T.; Hao, Z.; Bryan, L.; Singh, N.; Kochenderfer, J.N.; Zhou, G. The impact of antibiotic usage on the efficacy of chemoimmunotherapy is contingent on the source of tumor-reactive T cells. Oncotarget 2017, 8, 111931-111942. [CrossRef]

34. Xu, X.; Zhang, X. Effects of cyclophosphamide on immune system and gut microbiota in mice. Microbiol. Res. 2015, 171, 97-106. [CrossRef]

35. Araya, R.E.; Goldszmid, R.S. Two Bugs a NOD Away from Improving Cancer Therapy Efficacy. Immunity 2016, 45, 714-716. [CrossRef]

36. Bronckaers, A.; Balzarini, J.; Liekens, S. The cytostatic activity of pyrimidine nucleosides is strongly modulated by Mycoplasma hyorhinis infection: Implications for cancer therapy. Biochem. Pharmacol. 2008, 76, 188-197. [CrossRef]

37. Geller, L.T.; Barzily-Rokni, M.; Danino, T.; Jonas, O.H.; Shental, N.; Nejman, D.; Gavert, N.; Zwang, Y.; Cooper, Z.A.; Shee, K.; et al. Potential role of intratumor bacteria in mediating tumor resistance to the chemotherapeutic drug gemcitabine. Science 2017, 357, 1156-1160. [CrossRef]

38. Geller, L.T.; Straussman, R. Intratumoral bacteria may elicit chemoresistance by metabolizing anticancer agents. Mol. Cell. Oncol. 2018, 5, e1405139. [CrossRef]

39. Lehouritis, P.; Cummins, J.; Stanton, M.; Murphy, C.T.; McCarthy, F.O.; Reid, G.; Urbaniak, C.; Byrne, W.L.; Tangney, M. Local bacteria affect the efficacy of chemotherapeutic drugs. Sci. Rep. 2015, 5, 14554. [CrossRef] 
40. Vande Voorde, J.; Sabuncuoğlu, S.; Noppen, S.; Hofer, A.; Ranjbarian, F.; Fieuws, S.; Balzarini, J.; Liekens, S. Nucleoside-catabolizing Enzymes in Mycoplasma-infected Tumor Cell Cultures Compromise the Cytostatic Activity of the Anticancer Drug Gemcitabine. J. Biol. Chem. 2014, 289, 13054-13065. [CrossRef]

41. Yu, T.; Guo, F.; Yu, Y.; Sun, T.; Ma, D.; Han, J.; Qian, Y.; Kryczek, I.; Sun, D.; Nagarsheth, N.; et al. Fusobacterium nucleatum Promotes Chemoresistance to Colorectal Cancer by Modulating Autophagy. Cell 2017, 170, 548-563. [CrossRef]

42. Zhang, S.; Yang, Y.; Weng, W.; Guo, B.; Cai, G.; Ma, Y.; Cai, S. Fusobacterium nucleatum promotes chemoresistance to 5-fluorouracil by upregulation of BIRC3 expression in colorectal cancer. J. Exp. Clin. Cancer Res. 2019, 38, 14. [CrossRef]

43. Karasawa, H.; Miura, K.; Fujibuchi, W.; Ishida, K.; Kaneko, N.; Kinouchi, M.; Okabe, M.; Ando, T.; Murata, Y.; Sasaki, H.; et al. Down-regulation of cIAP2 enhances 5-FU sensitivity through the apoptotic pathway in human colon cancer cells. Cancer Sci. 2009, 100, 903-913. [CrossRef]

44. Paulos, C.M.; Wrzesinski, C.; Kaiser, A.; Hinrichs, C.S.; Chieppa, M.; Cassard, L.; Palmer, D.C.; Boni, A.; Muranski, P.; Yu, Z.; et al. Microbial translocation augments the function of adoptively transferred self/tumor-specific CD8+ T cells via TLR4 signaling. J. Clin. Investig. 2007, 117, 2197-2204. [CrossRef]

45. Uribe-Herranz, M.; Bittinger, K.; Rafail, S.; Guedan, S.; Pierini, S.; Tanes, C.; Ganetsky, A.; Morgan, M.A.; Gill, S.; Tanyi, J.L.; et al. Gut microbiota modulates adoptive cell therapy via CD8 $\alpha$ dendritic cells and IL-12. JCI Insight 2018, 3, e94952. [CrossRef]

46. Sivan, A.; Corrales, L.; Hubert, N.; Williams, J.B.; Aquino-Michaels, K.; Earley, Z.M.; Benyamin, F.W.; Man Lei, Y.; Jabri, B.; Alegre, M.-L.; et al. Commensal Bifidobacterium promotes antitumor immunity and facilitates anti-PD-L1 efficacy. Science 2015, 350, 1084-1089. [CrossRef]

47. Vetizou, M.; Pitt, J.M.; Daillere, R.; Lepage, P.; Waldschmitt, N.; Flament, C.; Rusakiewicz, S.; Routy, B.; Roberti, M.P.; Duong, C.P.M.; et al. Anticancer immunotherapy by CTLA-4 blockade relies on the gut microbiota. Science 2015, 350, 1079-1084. [CrossRef]

48. Chaput, N.; Lepage, P.; Coutzac, C.; Soularue, E.; Le Roux, K.; Monot, C.; Boselli, L.; Routier, E.; Cassard, L.; Collins, M.; et al. Baseline gut microbiota predicts clinical response and colitis in metastatic melanoma patients treated with ipilimumab. Ann. Oncol. 2017, 28, 1368-1379. [CrossRef]

49. Gopalakrishnan, V.; Spencer, C.N.; Nezi, L.; Reuben, A.; Andrews, M.C.; Karpinets, T.V.; Prieto, P.A.; Vicente, D.; Hoffman, K.; Wei, S.C.; et al. Gut microbiome modulates response to anti-PD-1 immunotherapy in melanoma patients. Science 2018, 359, 97-103. [CrossRef]

50. Matson, V.; Fessler, J.; Bao, R.; Chongsuwat, T.; Zha, Y.; Alegre, M.-L.; Luke, J.J.; Gajewski, T.F. The commensal microbiome is associated with anti-PD-1 efficacy in metastatic melanoma patients. Science 2018, 359, $104-108$. [CrossRef]

51. Routy, B.; Le Chatelier, E.; Derosa, L.; Duong, C.P.M.; Alou, M.T.; Daillère, R.; Fluckiger, A.; Messaoudene, M.; Rauber, C.; Roberti, M.P.; et al. Gut microbiome influences efficacy of PD-1-based immunotherapy against epithelial tumors. Science 2018, 359, 91-97. [CrossRef]

52. Tanoue, T.; Morita, S.; Plichta, D.R.; Skelly, A.N.; Suda, W.; Sugiura, Y.; Narushima, S.; Vlamakis, H.; Motoo, I.; Sugita, K.; et al. A defined commensal consortium elicits CD8 T cells and anti-cancer immunity. Nature 2019, 565, 600-605. [CrossRef]

53. Pitt, J.M.; Vetizou, M.; Waldschmitt, N.; Kroemer, G.; Chamaillard, M.; Boneca, I.G.; Zitvogel, L. Fine-Tuning Cancer Immunotherapy: Optimizing the Gut Microbiome. Cancer Res. 2016, 76, 4602-4607. [CrossRef]

54. Goldszmid, R.S.; Dzutsev, A.; Viaud, S.; Zitvogel, L.; Restifo, N.P.; Trinchieri, G. Microbiota modulation of myeloid cells in cancer therapy. Cancer Immunol. Res. 2015, 3, 103-109. [CrossRef]

55. Gorjifard, S.; Goldszmid, R.S. Beating Cancer with a Gut Feeling. Cell Host Microbe 2015, 18, 646-648. [CrossRef]

56. Dubin, K.; Callahan, M.K.; Ren, B.; Khanin, R.; Viale, A.; Ling, L.; No, D.; Gobourne, A.; Littmann, E.; Huttenhower, C.; et al. Intestinal microbiome analyses identify melanoma patients at risk for checkpoint-blockade-induced colitis. Nat. Commun. 2016, 7. [CrossRef]

57. Frankel, A.E.; Deshmukh, S.; Reddy, A.; Lightcap, J.; Hayes, M.; McClellan, S.; Singh, S.; Rabideau, B.; Glover, T.G.; Roberts, B.; et al. Cancer Immune Checkpoint Inhibitor Therapy and the Gut Microbiota. Integr. Cancer Ther. 2019, 18, 153473541984637. [CrossRef] 
58. Elkrief, A.; El Raichani, L.; Richard, C.; Messaoudene, M.; Belkaid, W.; Malo, J.; Belanger, K.; Miller, W.; Jamal, R.; Letarte, N.; et al. Antibiotics are associated with decreased progression-free survival of advanced melanoma patients treated with immune checkpoint inhibitors. Oncoimmunology 2019, 8, e1568812. [CrossRef]

59. Roy, S.; Trinchieri, G. Microbiota: A key orchestrator of cancer therapy. Nat. Rev. Cancer 2017, 17, $271-285$. [CrossRef]

60. Baskar, R.; Dai, J.; Wenlong, N.; Yeo, R.; Yeoh, K.-W. Biological response of cancer cells to radiation treatment. Front. Mol. Biosci. 2014, 1, 24. [CrossRef]

61. Kroemer, G.; Galluzzi, L.; Kepp, O.; Zitvogel, L. Immunogenic cell death in cancer therapy. Annu. Rev. Immunol. 2013, 31, 51-72. [CrossRef]

62. Barker, H.E.; Paget, J.T.E.; Khan, A.A.; Harrington, K.J. The tumour microenvironment after radiotherapy: Mechanisms of resistance and recurrence. Nat. Rev. Cancer 2015, 15, 409-425. [CrossRef]

63. Cui, M.; Xiao, H.; Luo, D.; Zhang, X.; Zhao, S.; Zheng, Q.; Li, Y.; Zhao, Y.; Dong, J.; Li, H.; et al. Circadian rhythm shapes the gut microbiota affecting host radiosensitivity. Int. J. Mol. Sci. 2016, 17, 1786. [CrossRef]

64. Cui, M.; Xiao, H.; Li, Y.; Zhou, L.; Zhao, S.; Luo, D.; Zheng, Q.; Dong, J.; Zhao, Y.; Zhang, X.; et al. Faecal microbiota transplantation protects against radiation-induced toxicity. EMBO Mol. Med. 2017, 9, 448-461. [CrossRef]

65. Kuwahara, Y.; Oikawa, T.; Ochiai, Y.; Roudkenar, M.H.; Fukumoto, M.; Shimura, T.; Ohtake, Y.; Ohkubo, Y.; Mori, S.; Uchiyama, Y.; et al. Enhancement of autophagy is a potential modality for tumors refractory to radiotherapy. Cell Death Dis. 2011, 2, e177.

66. Digomann, D.; Kurth, I.; Tyutyunnykova, A.; Chen, O.; Löck, S.; Gorodetska, I.; Peitzsch, C.; Skvortsova, I.-I.; Negro, G.; Aschenbrenner, B.; et al. The CD98 Heavy Chain Is a Marker and Regulator of Head and Neck Squamous Cell Carcinoma Radiosensitivity. Clin. Cancer Res. 2019, 25, 3152-3163. [CrossRef]

67. Digomann, D.; Linge, A.; Dubrovska, A. SLC3A2/CD98hc, autophagy and tumor radioresistance: A link confirmed. Autophagy 2019, 15, 1850-1851. [CrossRef]

68. Ferreira, M.R.; Muls, A.; Dearnaley, D.P.; Andreyev, H.J.N. Microbiota and radiation-induced bowel toxicity: Lessons from inflammatory bowel disease for the radiation oncologist. Lancet Oncol. 2014, 15, e139-e147. [CrossRef]

69. Reis Ferreira, M.; Andreyev, J.; Mohammed, K.; Truelove, L.; Gowan, S.M.; Li, J.; Gulliford, S.L.; Marchesi, J.; Dearnaley, D.P. Microbiota and radiotherapy-induced gastrointestinal side-effects (MARS) study: A large pilot study of the microbiome in acute and late radiation enteropathy. Clin. Cancer Res. 2019. [CrossRef]

70. Gerassy-Vainberg, S.; Blatt, A.; Danin-Poleg, Y.; Gershovich, K.; Sabo, E.; Nevelsky, A.; Daniel, S.; Dahan, A.; Ziv, O.; Dheer, R.; et al. Radiation induces proinflammatory dysbiosis: Transmission of inflammatory susceptibility by host cytokine induction. Gut 2018, 67, 97-107. [CrossRef]

71. Nam, Y.-D.; Kim, H.J.; Seo, J.-G.; Kang, S.W.; Bae, J.-W. Impact of pelvic radiotherapy on gut microbiota of gynecological cancer patients revealed by massive pyrosequencing. PLoS ONE 2013, 8, e82659. [CrossRef]

72. Wang, A.; Ling, Z.; Yang, Z.; Kiela, P.R.; Wang, T.; Wang, C.; Cao, L.; Geng, F.; Shen, M.; Ran, X.; et al. Gut Microbial Dysbiosis May Predict Diarrhea and Fatigue in Patients Undergoing Pelvic Cancer Radiotherapy: A Pilot Study. PLoS ONE 2015, 10, e0126312. [CrossRef]

73. Wang, Z.; Wang, Q.; Wang, X.; Zhu, L.; Chen, J.; Zhang, B.; Chen, Y.; Yuan, Z. Gut microbial dysbiosis is associated with development and progression of radiation enteritis during pelvic radiotherapy. J. Cell. Mol. Med. 2019, 23, 3747-3756. [CrossRef]

74. Hekmatshoar, Y.; Saadat, Y.R.; Khatibi, S.M.H.; Ozkan, T.; Vahed, F.Z.; Nariman-Saleh-Fam, Z.; Gargari, B.P.; Sunguroglu, A.; Vahed, S.Z. The impact of tumor and gut microbiotas on cancer therapy; Beneficial or detrimental? Life Sci. 2019, 233, 116680. [CrossRef]

75. Olivas, A.D.; Shogan, B.D.; Valuckaite, V.; Zaborin, A.; Belogortseva, N.; Musch, M.; Meyer, F.; Trimble, W.L.; An, G.; Gilbert, J.; et al. Intestinal Tissues Induce an SNP Mutation in Pseudomonas aeruginosa That Enhances Its Virulence: Possible Role in Anastomotic Leak. PLoS ONE 2012, 7, e44326.

76. Al-Qadami, G.; Van Sebille, Y.; Le, H.; Bowen, J. Gut microbiota: Implications for radiotherapy response and radiotherapy-induced mucositis. Expert Rev. Gastroenterol. Hepatol. 2019, 13, 485-496. [CrossRef]

77. Ashraf, S.Q.; Burns, E.M.; Jani, A.; Altman, S.; Young, J.D.; Cunningham, C.; Faiz, O.; Mortensen, N.J. The economic impact of anastomotic leakage after anterior resections in English NHS hospitals: Are we adequately remunerating them? Colorectal Dis. 2013, 15, e190-e198. [CrossRef] 
78. Buchs, N.C.; Gervaz, P.; Secic, M.; Bucher, P.; Mugnier-Konrad, B.; Morel, P. Incidence, consequences, and risk factors for anastomotic dehiscence after colorectal surgery: A prospective monocentric study. Int. J. Colorectal Dis. 2008, 23, 265-270. [CrossRef]

79. Goto, S.; Hasegawa, S.; Hida, K.; Uozumi, R.; Kanemitsu, Y.; Watanabe, T.; Sugihara, K.; Sakai, Y. Multicenter analysis of impact of anastomotic leakage on long-term oncologic outcomes after curative resection of colon cancer. Surgery 2017, 162, 317-324. [CrossRef]

80. Hammond, J.; Lim, S.; Wan, Y.; Gao, X.; Patkar, A. The Burden of Gastrointestinal Anastomotic Leaks: An Evaluation of Clinical and Economic Outcomes. J. Gastrointest. Surg. 2014, 18, 1176-1185. [CrossRef]

81. Mirnezami, A.; Mirnezami, R.; Chandrakumaran, K.; Sasapu, K.; Sagar, P.; Finan, P. Increased Local Recurrence and Reduced Survival from Colorectal Cancer Following Anastomotic Leak: Systematic Review and Meta-Analysis. Ann. Surg. 2011, 253, 890-899. [CrossRef]

82. Alves, A.; Panis, Y.; Trancar, D.; Regimbeau, J.M.; Pocard, M.; Valleur, P. Factors Associated with Clinically Significant Anastomotic Leakage after Large Bowel Resection: Multivariate Analysis of 707 Patients. World J. Surg. 2002, 26, 499-502.

83. Borowski, D.W.; Bradburn, D.M.; Mills, S.J.; Bharathan, B.; Wilson, R.G.; Ratcliffe, A.A.; Kelly, S.B. Volume-outcome analysis of colorectal cancer-related outcomes. Br. J. Surg. 2010, 97, 1416-1430. [CrossRef]

84. Frasson, M.; Granero-Castro, P.; Ramos Rodríguez, J.L.; Flor-Lorente, B.; Braithwaite, M.; Martí Martínez, E.; Álvarez Pérez, J.A.; Codina Cazador, A.; Espí, A.; Garcia-Granero, E.; et al. Risk factors for anastomotic leak and postoperative morbidity and mortality after elective right colectomy for cancer: Results from a prospective, multicentric study of 1102 patients. Int. J. Colorectal Dis. 2016, 31, 105-114. [CrossRef]

85. Hyman, N.; Manchester, T.L.; Osler, T.; Burns, B.; Cataldo, P.A. Anastomotic Leaks After Intestinal Anastomosis: It's Later Than You Think. Ann. Surg. 2007, 245, 254-258. [CrossRef]

86. Chen, E.B.; Cason, C.; Gilbert, J.A.; Ho, K.J. Current State of Knowledge on Implications of Gut Microbiome for Surgical Conditions. J. Gastrointest. Surg. 2018, 22, 1112-1123. [CrossRef]

87. Alverdy, J.C.; Hyoju, S.K.; Weigerinck, M.; Gilbert, J.A. The gut microbiome and the mechanism of surgical infection: The gut microbiome and the mechanism of surgical infection. Br. J. Surg. 2017, 104, e14-e23. [CrossRef]

88. Gaines, S.; Shao, C.; Hyman, N.; Alverdy, J.C. Gut microbiome influences on anastomotic leak and recurrence rates following colorectal cancer surgery: Gut microbiome and outcomes after colorectal cancer surgery. Br. J. Surg. 2018, 105, e131-e141. [CrossRef]

89. Guyton, K.; Alverdy, J.C. The gut microbiota and gastrointestinal surgery. Nat. Rev. Gastroenterol. Hepatol. 2017, 14, 43-54. [CrossRef]

90. Hajjar, R.; Santos, M.M.; Dagbert, F.; Richard, C.S. Current evidence on the relation between gut microbiota and intestinal anastomotic leak in colorectal surgery. Am. J. Surg. 2019. [CrossRef]

91. Russ, A.; Casillas, M. Gut Microbiota and Colorectal Surgery: Impact on Postoperative Complications. Clin. Colon Rectal Surg. 2016, 29, 253-257.

92. Cohn, I.; Gelb, A.; Hawthorne, H.R. Strangulation obstruction-the effect of pre- and post-operative antibacterial agents. Ann. Surg. 1953, 138, 748-758. [CrossRef]

93. Cohn, I.; Rives, J.D. Antibiotic Protection of Colon Anastomoses. Ann. Surg. 1955, 141, 707-717. [CrossRef]

94. Rollins, K.E.; Javanmard-Emamghissi, H.; Acheson, A.G.; Lobo, D.N. The Role of Oral Antibiotic Preparation in Elective Colorectal Surgery: A Meta-analysis. Ann. Surg. 2019, 270, 43-58. [CrossRef]

95. Van Praagh, J.B.; de Goffau, M.C.; Bakker, I.S.; van Goor, H.; Harmsen, H.J.M.; Olinga, P.; Havenga, K. Mucus Microbiome of Anastomotic Tissue During Surgery Has Predictive Value for Colorectal Anastomotic Leakage. Ann. Surg. 2019, 269, 911-916. [CrossRef]

96. Stern, J.R.; Olivas, A.D.; Valuckaite, V.; Zaborina, O.; Alverdy, J.C.; An, G. Agent-based model of epithelial host-pathogen interactions in anastomotic leak. J. Surg. Res. 2013, 184, 730-738. [CrossRef]

97. Seal, J.B.; Alverdy, J.C.; Zaborina, O.; An, G. Agent-based dynamic knowledge representation of Pseudomonas aeruginosa virulence activation in the stressed gut: Towards characterizing host-pathogen interactions in gut-derived sepsis. Theor. Biol. Med. Model. 2011, 8, 33. [CrossRef]

98. Wu, L.; Holbrook, C.; Zaborina, O.; Ploplys, E.; Rocha, F.; Pelham, D.; Chang, E.; Musch, M.; Alverdy, J. Pseudomonas aeruginosa Expresses a Lethal Virulence Determinant, the PA-I Lectin/Adhesin, in the Intestinal Tract of a Stressed Host: The Role of Epithelia Cell Contact and Molecules of the Quorum Sensing Signaling System. Ann. Surg. 2003, 238, 754-764. [CrossRef] 
99. Bloemen, J.G.; Schreinemacher, M.H.; de Bruine, A.P.; Buurman, W.A.; Bouvy, N.D.; Dejong, C.H. Butyrate Enemas Improve Intestinal Anastomotic Strength in a Rat Model. Dis. Colon Rectum 2010, 53, 1069-1075. [CrossRef]

100. Mathew, A.J.; Wann, V.C.; Abraham, D.T.; Jacob, P.M.; Selvan, B.S.; Ramakrishna, B.S.; Nair, A.N. The Effect of Butyrate on the Healing of Colonic Anastomoses in Rats. J. Investig. Surg. 2010, 23, 101-104. [CrossRef]

101. Levison, M.E. Effect of colon flora and short-chain fatty acids on growth in vitro of Pseudomonas aeruginsoa and Enterobacteriaceae. Infect. Immun. 1973, 8, 30-35.

102. Shogan, B.D.; Belogortseva, N.; Luong, P.M.; Zaborin, A.; Lax, S.; Bethel, C.; Ward, M.; Muldoon, J.P.; Singer, M.; An, G.; et al. Collagen degradation and MMP9 activation by Enterococcus faecalis contribute to intestinal anastomotic leak. Sci. Transl. Med. 2015, 7, 286ra68. [CrossRef]

103. Helmink, B.A.; Khan, M.A.W.; Hermann, A.; Gopalakrishnan, V.; Wargo, J.A. The microbiome, cancer, and cancer therapy. Nat. Med. 2019, 25, 377-388. [CrossRef]

104. Vivarelli, S.; Salemi, R.; Candido, S.; Falzone, L.; Santagati, M.; Stefani, S.; Torino, F.; Banna, G.L.; Tonini, G.; Libra, M. Gut Microbiota and Cancer: From Pathogenesis to Therapy. Cancers 2019, 11, 38. [CrossRef]

105. Nagano, T.; Otoshi, T.; Hazama, D.; Kiriu, T.; Umezawa, K.; Katsurada, N.; Nishimura, Y. Novel cancer therapy targeting microbiome. OncoTargets Ther. 2019, 12, 3619-3624. [CrossRef]

106. Huemer, F.; Rinnerthaler, G.; Westphal, T.; Hackl, H.; Hutarew, G.; Gampenrieder, S.P.; Weiss, L.; Greil, R. Impact of antibiotic treatment on immune-checkpoint blockade efficacy in advanced non-squamous non-small cell lung cancer. Oncotarget 2018, 9, 16512-16520. [CrossRef]

107. Elkrief, A.; Derosa, L.; Kroemer, G.; Zitvogel, L.; Routy, B. The negative impact of antibiotics on outcomes in cancer patients treated with immunotherapy: A new independent prognostic factor? Ann. Oncol. 2019, mdz206. [CrossRef]

108. Ahmed, J.; Kumar, A.; Parikh, K.; Anwar, A.; Knoll, B.M.; Puccio, C.; Chun, H.; Fanucchi, M.; Lim, S.H. Use of broad-spectrum antibiotics impacts outcome in patients treated with immune checkpoint inhibitors. OncoImmunology 2018, 7, e1507670. [CrossRef]

109. Hakozaki, T.; Okuma, Y.; Omori, M.; Hosomi, Y. Impact of prior antibiotic use on the efficacy of nivolumab for non-small cell lung cancer. Oncol. Lett. 2019, 17, 2946-2952. [CrossRef]

110. Derosa, L.; Routy, B.; Enot, D.; Baciarello, G.; Massard, C.; Loriot, Y.; Fizazi, K.; Escudier, B.J.; Zitvogel, L.; Albiges, L. Impact of antibiotics on outcome in patients with metastatic renal cell carcinoma treated with immune checkpoint inhibitors. J. Clin. Oncol. 2017, 35, 462. [CrossRef]

111. Cougnoux, A.; Delmas, J.; Gibold, L.; Faïs, T.; Romagnoli, C.; Robin, F.; Cuevas-Ramos, G.; Oswald, E.; Darfeuille-Michaud, A.; Prati, F.; et al. Small-molecule inhibitors prevent the genotoxic and protumoural effects induced by colibactin-producing bacteria. Gut 2016, 65, 278-285. [CrossRef]

112. Gough, E.; Shaikh, H.; Manges, A.R. Systematic Review of Intestinal Microbiota Transplantation (Fecal Bacteriotherapy) for Recurrent Clostridium difficile Infection. Clin. Infect. Dis. 2011, 53, 994-1002. [CrossRef]

113. Food and Agriculture Organization of the United Nations; World Health Organization; Health Organization. Health and Nutritional Properties of Probiotics in Food including Powder Milk and Live Lactic Acid Bacteria. In Report of a Joint FAO/WHO Expert Consultation on Evaluation of Health and Nutritional Properties of Probiotics in Food Including Powder Milk with Live Lactic Acid Bacteria; FAO/WHO: Córdoba, Argentina, 2001.

114. Hill, C.; Guarner, F.; Reid, G.; Gibson, G.R.; Merenstein, D.J.; Pot, B.; Morelli, L.; Canani, R.B.; Flint, H.J.; Salminen, S.; et al. Expert consensus document. The International Scientific Association for Probiotics and Prebiotics consensus statement on the scope and appropriate use of the term probiotic. Nat. Rev. Gastroenterol. Hepatol. 2014, 11, 506-514. [CrossRef]

115. Kristensen, N.B.; Bryrup, T.; Allin, K.H.; Nielsen, T.; Hansen, T.H.; Pedersen, O. Alterations in fecal microbiota composition by probiotic supplementation in healthy adults: A systematic review of randomized controlled trials. Genome Med. 2016, 8, 52. [CrossRef]

116. Hassan, H.; Rompola, M.; Glaser, A.W.; Kinsey, S.E.; Phillips, R.S. Systematic review and meta-analysis investigating the efficacy and safety of probiotics in people with cancer. Support. Care Cancer 2018, 26, 2503-2509. [CrossRef]

117. Hendler, R.; Zhang, Y. Probiotics in the Treatment of Colorectal Cancer. Medicines 2018, 5, 101. [CrossRef]

118. Górska, A.; Przystupski, D.; Niemczura, M.J.; Kulbacka, J. Probiotic Bacteria: A Promising Tool in Cancer Prevention and Therapy. Curr. Microbiol. 2019, 76, 939-949. [CrossRef] 
119. Okawa, T.; Niibe, H.; Arai, T.; Sekiba, K.; Noda, K.; Takeuchi, S.; Hashimoto, S.; Ogawa, N. Effect of lc9018 combined with radiation therapy on carcinoma of the uterine cervix. A phase iii, multicenter, randomized, controlled study. Cancer 1993, 72, 1949-1954. [CrossRef]

120. Ciorba, M.A.; Riehl, T.E.; Rao, M.S.; Moon, C.; Ee, X.; Nava, G.M.; Walker, M.R.; Marinshaw, J.M.; Stappenbeck, T.S.; Stenson, W.F. Lactobacillus probiotic protects intestinal epithelium from radiation injury in a TLR-2/cyclo-oxygenase-2-dependent manner. Gut 2012, 61, 829-838. [CrossRef]

121. Delia, P.; Sansotta, G.; Donato, V.; Frosina, P.; Messina, G.; De Renzis, C.; Famularo, G. Use of probiotics for prevention of radiation-induced diarrhea. World J. Gastroenterol. 2007, 13, 912-915. [CrossRef]

122. Jiang, C.; Wang, H.; Xia, C.; Dong, Q.; Chen, E.; Qiu, Y.; Su, Y.; Xie, H.; Zeng, L.; Kuang, J.; et al. A randomized, double-blind, placebo-controlled trial of probiotics to reduce the severity of oral mucositis induced by chemoradiotherapy for patients with nasopharyngeal carcinoma. Cancer 2019, 125, 1081-1090. [CrossRef]

123. Consoli, M.L.D.; da Silva, R.S.; Nicoli, J.R.; Bruña-Romero, O.; da Silva, R.G.; de Vasconcelos Generoso, S.; Correia, M.I.T.D. Randomized Clinical Trial: Impact of Oral Administration of Saccharomyces boulardii on Gene Expression of Intestinal Cytokines in Patients Undergoing Colon Resection. J. Parenter. Enter. Nutr. 2016, 40, 1114-1121. [CrossRef]

124. Louis, P.; Hold, G.L.; Flint, H.J. The gut microbiota, bacterial metabolites and colorectal cancer. Nat. Rev. Microbiol. 2014, 12, 661-672. [CrossRef]

125. Gibson, G.R.; Hutkins, R.; Sanders, M.E.; Prescott, S.L.; Reimer, R.A.; Salminen, S.J.; Scott, K.; Stanton, C.; Swanson, K.S.; Cani, P.D.; et al. Expert consensus document: The International Scientific Association for Probiotics and Prebiotics (ISAPP) consensus statement on the definition and scope of prebiotics. Nat. Rev. Gastroenterol. Hepatol. 2017, 14, 491-502. [CrossRef]

126. Taur, Y.; Jenq, R.R.; Perales, M.-A.; Littmann, E.R.; Morjaria, S.; Ling, L.; No, D.; Gobourne, A.; Viale, A.; Dahi, P.B.; et al. The effects of intestinal tract bacterial diversity on mortality following allogeneic hematopoietic stem cell transplantation. Blood 2014, 124, 1174-1182. [CrossRef]

127. Sommacal, H.M.; Bersch, V.P.; Vitola, S.P.; Osvaldt, A.B. Perioperative Synbiotics Decrease Postoperative Complications in Periampullary Neoplasms: A Randomized, Double-Blind Clinical Trial. Nutr. Cancer 2015, 67, 457-462. [CrossRef]

128. Song, M.; Chan, A.T. The Potential Role of Exercise and Nutrition in Harnessing the Immune System to Improve Colorectal Cancer Survival. Gastroenterology 2018, 155, 596-600. [CrossRef]

129. Lahiri, S.; Kim, H.; Garcia-Perez, I.; Reza, M.M.; Martin, K.A.; Kundu, P.; Cox, L.M.; Selkrig, J.; Posma, J.M.; Zhang, H.; et al. The gut microbiota influences skeletal muscle mass and function in mice. Sci. Transl. Med. 2019, 11, eaan5662. [CrossRef]

130. Ticinesi, A.; Nouvenne, A.; Cerundolo, N.; Catania, P.; Prati, B.; Tana, C.; Meschi, T. Gut Microbiota, Muscle Mass and Function in Aging: A Focus on Physical Frailty and Sarcopenia. Nutrients 2019, 11, 1633. [CrossRef]

131. Nay, K.; Jollet, M.; Goustard, B.; Baati, N.; Vernus, B.; Pontones, M.; Lefeuvre-Orfila, L.; Bendavid, C.; Rué, O.; Mariadassou, M.; et al. Gut bacteria are critical for optimal muscle function: A potential link with glucose homeostasis. Am. J. Physiol. Endocrinol. Metab. 2019, 317, e158-e171. [CrossRef]

132. Yan, H.; Diao, H.; Xiao, Y.; Li, W.; Yu, B.; He, J.; Yu, J.; Zheng, P.; Mao, X.; Luo, Y.; et al. Gut microbiota can transfer fiber characteristics and lipid metabolic profiles of skeletal muscle from pigs to germ-free mice. Sci. Rep. 2016, 6, 31786. [CrossRef]

133. Chang, K.-V.; Chen, J.-D.; Wu, W.-T.; Huang, K.-C.; Hsu, C.-T.; Han, D.-S. Association between Loss of Skeletal Muscle Mass and Mortality and Tumor Recurrence in Hepatocellular Carcinoma: A Systematic Review and Meta-Analysis. Liver Cancer 2018, 7, 90-103. [CrossRef]

134. Fujiwara, N.; Nakagawa, H.; Kudo, Y.; Tateishi, R.; Taguri, M.; Watadani, T.; Nakagomi, R.; Kondo, M.; Nakatsuka, T.; Minami, T.; et al. Sarcopenia, intramuscular fat deposition, and visceral adiposity independently predict the outcomes of hepatocellular carcinoma. J. Hepatol. 2015, 63, 131-140. [CrossRef]

135. Van Vugt, J.L.A.; Coebergh van den Braak, R.R.J.; Lalmahomed, Z.S.; Vrijland, W.W.; Dekker, J.W.T.; Zimmerman, D.D.E.; Vles, W.J.; Coene, P.-P.L.O.; IJzermans, J.N.M. Impact of low skeletal muscle mass and density on short and long-term outcome after resection of stage I-III colorectal cancer. Eur. J. Surg. Oncol. 2018, 44, 1354-1360. [CrossRef] 
136. Van der Kroft, G.; Bours, D.M.J.L.; Janssen-Heijnen, D.M.; van Berlo, D.C.L.H.; Konsten, D.J.L.M. Value of sarcopenia assessed by computed tomography for the prediction of postoperative morbidity following oncological colorectal resection: A comparison with the malnutrition screening tool. Clin. Nutr. ESPEN 2018, 24, 114-119. [CrossRef]

137. Reisinger, K.W.; Bosmans, J.W.A.M.; Uittenbogaart, M.; Alsoumali, A.; Poeze, M.; Sosef, M.N.; Derikx, J.P.M. Loss of Skeletal Muscle Mass During Neoadjuvant Chemoradiotherapy Predicts Postoperative Mortality in Esophageal Cancer Surgery. Ann. Surg. Oncol. 2015, 22, 4445-4452. [CrossRef]

138. Qiu, S.; Jiang, C.; Zhou, L. Physical activity and mortality in patients with colorectal cancer: A meta-analysis of prospective cohort studies. Eur. J. Cancer Prev. 2019. [CrossRef]

139. Schieber, A.M.P.; Lee, Y.M.; Chang, M.W.; Leblanc, M.; Collins, B.; Downes, M.; Evans, R.M.; Ayres, J.S. Disease tolerance mediated by microbiome E. coli involves inflammasome and IGF-1 signaling. Science 2015, 350, 558-563. [CrossRef]

140. Bindels, L.B.; Beck, R.; Schakman, O.; Martin, J.C.; De Backer, F.; Sohet, F.M.; Dewulf, E.M.; Pachikian, B.D.; Neyrinck, A.M.; Thissen, J.-P.; et al. Restoring specific lactobacilli levels decreases inflammation and muscle atrophy markers in an acute leukemia mouse model. PLoS ONE 2012, 7, e37971. [CrossRef]

141. Varian, B.J.; Gourishetti, S.; Poutahidis, T.; Lakritz, J.R.; Levkovich, T.; Kwok, C.; Teliousis, K.; Ibrahim, Y.M.; Mirabal, S.; Erdman, S.E. Beneficial bacteria inhibit cachexia. Oncotarget 2016, 7, 11803-11816. [CrossRef]

142. Bindels, L.B.; Neyrinck, A.M.; Claus, S.P.; Le Roy, C.I.; Grangette, C.; Pot, B.; Martinez, I.; Walter, J.; Cani, P.D.; Delzenne, N.M. Synbiotic approach restores intestinal homeostasis and prolongs survival in leukaemic mice with cachexia. ISME J. 2016, 10, 1456-1470. [CrossRef]

143. Bindels, L.B.; Neyrinck, A.M.; Salazar, N.; Taminiau, B.; Druart, C.; Muccioli, G.G.; François, E.; Blecker, C.; Richel, A.; Daube, G.; et al. Non Digestible Oligosaccharides Modulate the Gut Microbiota to Control the Development of Leukemia and Associated Cachexia in Mice. PLoS ONE 2015, 10, e0131009. [CrossRef]

144. Pötgens, S.A.; Brossel, H.; Sboarina, M.; Catry, E.; Cani, P.D.; Neyrinck, A.M.; Delzenne, N.M.; Bindels, L.B. Klebsiella oxytoca expands in cancer cachexia and acts as a gut pathobiont contributing to intestinal dysfunction. Sci. Rep. 2018, 8, 12321. [CrossRef]

145. Schmid, D.; Leitzmann, M.F. Association between physical activity and mortality among breast cancer and colorectal cancer survivors: A systematic review and meta-analysis. Ann. Oncol. 2014, 25, 1293-1311. [CrossRef]

146. Nadler, M.B.; Desnoyers, A.; Langelier, D.M.; Amir, E. The effect of exercise on quality of life, fatigue, physical function and safety in advanced solid tumor cancers: A meta-analysis of randomized control trials. J. Pain Symptom Manag. 2019. [CrossRef]

147. Liu, L.; He, X.; Feng, L. Exercise on quality of life and cancer-related fatigue for lymphoma survivors: A systematic review and meta-analysis. Support. Care Cancer 2019, 1-14. [CrossRef]

148. Wang, J.; Huang, L.; Gao, Y.; Wang, Y.; Chen, S.; Huang, J.; Zheng, W.; Bao, P.; Gong, Y.; Zhang, Y.; et al. Physically active individuals have a $23 \%$ lower risk of any colorectal neoplasia and a $27 \%$ lower risk of advanced colorectal neoplasia than their non-active counterparts: Systematic review and meta-analysis of observational studies. Br. J. Sports Med. 2019. [CrossRef]

149. Rosero, I.D.; Ramírez-Vélez, R.; Lucia, A.; Martínez-Velilla, N.; Santos-Lozano, A.; Valenzuela, P.L.; Morilla, I.; Izquierdo, M. Systematic Review and Meta-Analysis of Randomized, Controlled Trials on Preoperative Physical Exercise Interventions in Patients with Non-Small-Cell Lung Cancer. Cancers 2019, 11,944. [CrossRef]

150. Ashcraft, K.A.; Warner, A.B.; Jones, L.W.; Dewhirst, M.W. Exercise as Adjunct Therapy in Cancer. Semin. Radiat. Oncol. 2019, 29, 16-24. [CrossRef]

151. Oruç, Z.; Kaplan, M.A. Effect of exercise on colorectal cancer prevention and treatment. World J. Gastrointest. Oncol. 2019, 11, 348-366. [CrossRef]

152. Courneya, K.S.; Vardy, J.L.; O'Callaghan, C.J.; Friedenreich, C.M.; Campbell, K.L.; Prapavessis, H.; Crawford, J.J.; O'Brien, P.; Dhillon, H.M.; Jonker, D.J.; et al. Effects of a Structured Exercise Program on Physical Activity and Fitness in Colon Cancer Survivors: One Year Feasibility Results from the CHALLENGE Trial. Cancer Epidemiol. Biomark. Prev. 2016, 25, 969-977. [CrossRef]

153. Zhang, X.; Ashcraft, K.A.; Betof Warner, A.; Nair, S.K.; Dewhirst, M.W. Can Exercise-Induced Modulation of the Tumor Physiologic Microenvironment Improve Antitumor Immunity? Cancer Res. 2019, 79, 2447-2456. [CrossRef] 
154. Pedersen, L.; Idorn, M.; Olofsson, G.H.; Lauenborg, B.; Nookaew, I.; Hansen, R.H.; Johannesen, H.H.; Becker, J.C.; Pedersen, K.S.; Dethlefsen, C.; et al. Voluntary Running Suppresses Tumor Growth through Epinephrine- and IL-6-Dependent NK Cell Mobilization and Redistribution. Cell Metab. 2016, 23, 554-562. [CrossRef]

155. Hojman, P.; Gehl, J.; Christensen, J.F.; Pedersen, B.K. Molecular Mechanisms Linking Exercise to Cancer Prevention and Treatment. Cell Metab. 2018, 27, 10-21. [CrossRef]

156. Idorn, M.; Thor Straten, P. Exercise and cancer: From "healthy" to "therapeutic"? Cancer Immunol. Immunother. 2017, 66, 667-671. [CrossRef]

157. Nilsen, T.I.L.; Romundstad, P.R.; Petersen, H.; Gunnell, D.; Vatten, L.J. Recreational physical activity and cancer risk in subsites of the colon (the Nord-Trøndelag Health Study). Cancer Epidemiol. Biomark. Prev. 2008, 17, 183-188. [CrossRef]

158. Mailing, L.J.; Allen, J.M.; Buford, T.W.; Fields, C.J.; Woods, J.A. Exercise and the Gut Microbiome: A Review of the Evidence, Potential Mechanisms, and Implications for Human Health. Exerc. Sport Sci. Rev. 2019, 47, 75-85. [CrossRef]

159. Maillard, F.; Vazeille, E.; Sauvanet, P.; Sirvent, P.; Bonnet, R.; Combaret, L.; Chausse, P.; Chevarin, C.; Otero, Y.F.; Delcros, G.; et al. Preventive Effect of Spontaneous Physical Activity on the Gut-Adipose Tissue in a Mouse Model That Mimics Crohn's Disease Susceptibility. Cells 2019, 8, 33. [CrossRef]

160. Allen, J.M.; Mailing, L.J.; Cohrs, J.; Salmonson, C.; Fryer, J.D.; Nehra, V.; Hale, V.L.; Kashyap, P.; White, B.A.; Woods, J.A. Exercise training-induced modification of the gut microbiota persists after microbiota colonization and attenuates the response to chemically-induced colitis in gnotobiotic mice. Gut Microbes 2018, 9, 115-130. [CrossRef]

161. Lamoureux, E.V.; Grandy, S.A.; Langille, M.G.I. Moderate Exercise Has Limited but Distinguishable Effects on the Mouse Microbiome. mSystems 2017, 2. [CrossRef]

162. Denou, E.; Marcinko, K.; Surette, M.G.; Steinberg, G.R.; Schertzer, J.D. High-intensity exercise training increases the diversity and metabolic capacity of the mouse distal gut microbiota during diet-induced obesity. Am. J. Physiol. Endocrinol. Metab. 2016, 310, E982-E993. [CrossRef]

163. Allen, J.M.; Berg Miller, M.E.; Pence, B.D.; Whitlock, K.; Nehra, V.; Gaskins, H.R.; White, B.A.; Fryer, J.D.; Woods, J.A. Voluntary and forced exercise differentially alters the gut microbiome in C57BL/6J mice. J. Appl. Physiol. 2015, 118, 1059-1066. [CrossRef]

164. Lambert, J.E.; Myslicki, J.P.; Bomhof, M.R.; Belke, D.D.; Shearer, J.; Reimer, R.A. Exercise training modifies gut microbiota in normal and diabetic mice. Appl. Physiol. Nutr. Metab. 2015, 40, 749-752. [CrossRef]

165. Keohane, D.M.; Woods, T.; O'Connor, P.; Underwood, S.; Cronin, O.; Whiston, R.; O'Sullivan, O.; Cotter, P.; Shanahan, F.; Molloy, M.G.M. Four men in a boat: Ultra-endurance exercise alters the gut microbiome. J. Sci. Med. Sport 2019, 22, 1059-1064. [CrossRef]

166. Barton, W.; Penney, N.C.; Cronin, O.; Garcia-Perez, I.; Molloy, M.G.; Holmes, E.; Shanahan, F.; Cotter, P.D.; O'Sullivan, O. The microbiome of professional athletes differs from that of more sedentary subjects in composition and particularly at the functional metabolic level. Gut 2018, 67, 625-633. [CrossRef]

167. Clarke, S.F.; Murphy, E.F.; O’Sullivan, O.; Lucey, A.J.; Humphreys, M.; Hogan, A.; Hayes, P.; O’Reilly, M.; Jeffery, I.B.; Wood-Martin, R.; et al. Exercise and associated dietary extremes impact on gut microbial diversity. Gut 2014, 63, 1913-1920. [CrossRef]

168. Cronin, O.; Barton, W.; Skuse, P.; Penney, N.C.; Garcia-Perez, I.; Murphy, E.F.; Woods, T.; Nugent, H.; Fanning, A.; Melgar, S.; et al. A Prospective Metagenomic and Metabolomic Analysis of the Impact of Exercise and/or Whey Protein Supplementation on the Gut Microbiome of Sedentary Adults. mSystems 2018, 3. [CrossRef]

169. Newton, R.U.; Christophersen, C.T.; Fairman, C.M.; Hart, N.H.; Taaffe, D.R.; Broadhurst, D.; Devine, A.; Chee, R.; Tang, C.I.; Spry, N.; et al. Does exercise impact gut microbiota composition in men receiving androgen deprivation therapy for prostate cancer? A single-blinded, two-armed, randomised controlled trial. BMJ Open 2019, 9, e024872. [CrossRef]

170. Zackular, J.P.; Rogers, M.A.M.; Ruffin, M.T.; Schloss, P.D. The Human Gut Microbiome as a Screening Tool for Colorectal Cancer. Cancer Prev. Res. 2014, 7, 1112-1121. [CrossRef]

171. Bonnet, M.; Buc, E.; Sauvanet, P.; Darcha, C.; Dubois, D.; Pereira, B.; Déchelotte, P.; Bonnet, R.; Pezet, D.; Darfeuille-Michaud, A. Colonization of the human gut by E. coli and colorectal cancer risk. Clin. Cancer Res. 2014, 20, 859-867. [CrossRef] 
172. Villéger, R.; Lopès, A.; Veziant, J.; Gagnière, J.; Barnich, N.; Billard, E.; Boucher, D.; Bonnet, M. Microbial markers in colorectal cancer detection and/or prognosis. World J. Gastroenterol. 2018, 24, 2327-2347. [CrossRef]

173. Eklöf, V.; Löfgren-Burström, A.; Zingmark, C.; Edin, S.; Larsson, P.; Karling, P.; Alexeyev, O.; Rutegård, J.; Wikberg, M.L.; Palmqvist, R. Cancer-associated fecal microbial markers in colorectal cancer detection. Int. J. Cancer 2017, 141, 2528-2536. [CrossRef]

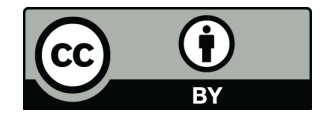

(C) 2019 by the authors. Licensee MDPI, Basel, Switzerland. This article is an open access article distributed under the terms and conditions of the Creative Commons Attribution (CC BY) license (http://creativecommons.org/licenses/by/4.0/). 